\title{
Climate-related migration and population health: social science-oriented dynamic simulation model
}

\author{
Rafael Reuveny
}

\begin{abstract}
Background: Social science models find the ecological impacts of climate change (EICC) contribute to internal migration in developing countries and, less so, international migration. Projections expect massive climate-related migration in this century. Nascent research calls to study health, migration, population, and armed conflict potential together, accounting for EICC and other factors. System science offers a way: develop a dynamic simulation model (DSM). We aim to validate the feasibility and usefulness of a pilot DSM intended to serve as a proof-of-concept and a basis for identifying model extensions to make it less simplified and more realistic.

Methods: Studies have separately examined essential parts. Our DSM integrates their results and computes composites of health problems (HP), health care (HC), non-EICC environmental health problems (EP), and environmental health services (ES) by origin site and by immigrants and natives in a destination site, and conflict risk and intensity per area. The exogenous variables include composites of EICC, sociopolitical, economic, and other factors. We simulate the model for synthetic input values and conduct sensitivity analyses.

Results: The simulation results refer to generic origin and destination sites anywhere on Earth. The effects' sizes are likely inaccurate from a real-world view, as our input values are synthetic. Their signs and dynamics are plausible, internally consistent, and, like the sizes, respond logically in sensitivity analyses. Climate migration may harm public health in a host area even with perfect HC/ES qualities and full access; and no HP spillovers across groups, conflict, EICC, and EP. Deviations from these conditions may worsen everyone's health. We consider adaptation options.

Conclusions: This work shows we can start developing DSMs to understand climate migration and public health by examining each case with its own inputs. Validation of our pilot model suggests we can use it as intended. We lay a path to making it more realistic for policy analysis.
\end{abstract}

Keywords: Interdisciplinary, System, Mathematical, Numerical, Sensitivity analysis, Validation

\section{Background}

In 1847-8, a typhus epidemic hit Prussia's poor Upper Silesia. The government turned to Doctor Virchow for advice, and he traveled to Upper Silesia. "Medicine," he argued in his report, "is a social science, and politics nothing else but medicine on a grand scale" [1]. His

Correspondence: rreuveny@indiana.edu

School of Public and Environmental Affairs, Indiana University, Bloomington, USA

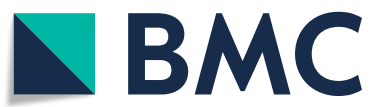

insight is relevant in our era of global climate change. The ecological impacts of climate change (EICC) can harm health directly (e.g., heat-related problems, extreme weather-related trauma) and indirectly (e.g., spreading pathogens, reducing food security, increasing the risk of armed conflict) [2]. ${ }^{1}$ Effects may vary by region, but researchers expect they will grow in this

\footnotetext{
${ }^{1}$ We define the abbreviations when introduced, at the end, and, as a reminder, in a few other places.
}

(c) The Author(s). 2021 Open Access This article is licensed under a Creative Commons Attribution 4.0 International License, which permits use, sharing, adaptation, distribution and reproduction in any medium or format, as long as you give appropriate credit to the original author(s) and the source, provide a link to the Creative Commons licence, and indicate if changes were made. The images or other third party material in this article are included in the article's Creative Commons licence, unless indicated otherwise in a credit line to the material. If material is not included in the article's Creative Commons licence and your intended use is not permitted by statutory regulation or exceeds the permitted use, you will need to obtain permission directly from the copyright holder. To view a copy of this licence, visit http://creativecommons.org/licenses/by/4.0/ The Creative Commons Public Domain Dedication waiver (http://creativecommons.org/publicdomain/zero/1.0/) applies to the data made available in this article, unless otherwise stated in a credit line to the data. 
century, especially if greenhouse gas emissions continue at current rates. People sidelined socially, politically, or economically are more vulnerable, especially in developing nations (the global South) [3].

EICC may elicit varied reactions. For example, people may do nothing, mitigate emissions, adapt in situ with defenses, or adjust by emigrating. Effective mitigation requires global cooperation. Poor people may be less able to adapt in situ than others and more inclined to relocate, all else the same. We call people migrating due to the combination of EICC and other factors climate migrants. Empirical social science research, we shall see, suggests EICC has contributed to migration in recent decades.

We aim to say something about climate migrants and health. In 2019, there were 272 million (M) authorized international immigrants globally (including $25.9 \mathrm{M}$ refugees, $164 \mathrm{M}$ workers, and $3.5 \mathrm{M}$ asylum-seekers), a new high absolutely and relative to the world population. Most of them moved from the South to developed nations (the Global North), or South-North, as did another 3.9-10 M who were stateless [4]. Another $58 \mathrm{M}$ immigrants were likely unauthorized, many South-North [5], $4 \mathrm{M}$ fled Venezuela [6], and $763 \mathrm{M}$ migrated internally (in-state)-also a new high-most in the South [7].

A recent global survey finds $710 \mathrm{M}$ people wish to migrate, almost all South-North [8]; most may not move. Projections suggest massive migration in this century. The United Nations projects $82 \mathrm{M}$ added South-North net migrants (in-out) by 2050 if the current economic and demographic trends continue [9]. Cities in the South may hold 1.5 billion more people by 2050 [10]; 40\% may be net internal migrants [11]. Projections for climate change consider a baseline without adaptation to and mitigation of carbon emissions (business as usual) and global climate tipping points. For example, floods and rising sea levels may add $200 \mathrm{M}$ migrants globally by 2050 [12]. The number of climate migrants by 2100 may be as high as $700 \mathrm{M}$ [13]. By 2050, rising sea levels, declining crop yields, and dwindling safe water may add $143 \mathrm{M}$ net internal migrants in Africa, Latin America, and South Asia [14]. Rising sea levels may add $187 \mathrm{M}$ migrants globally by 2100 [15]. In 2080-99, $236 \mathrm{M}$ people may leave African nations due to heat and rain anomalies [16]. In 2070-99, heat anomalies may add 20 $M$ asylum-seekers [17]. Current data imply these may move mainly within their nations, especially in the South, though many may move abroad.

These figures suggest it is prudent to study population health in the context of climate migrants. Research in this area is emerging and rarely explores climate, migration, and health together [18]. Studies survey health outcomes observed for modern-day immigrants as analogs for future climate migrants. For example, people forced to move by EICC and the associated adaption projects in the future may face infectious diseases, mental health problems, and health risks of EICC, pollution, and waste in coastal cities [2, 19-21]. Planned climate migrants may fare better [22]. Climate migrants may arrive broke and settle in areas facing health risks [10]. Health problems may reduce climate migration and rise on its way [23, 24]. EICC and Climate migrants may raise the risk of conflict in host areas. EICC and conflict may harm health and health care. The need for health care may top the ability to provide it $[25,26]$. The topic is complex, involving dynamic interconnections, feedbacks, multiple causal chains, trigger thresholds, integrated effects, and factors like health care, social, economic, political, demographic, environmental, and legal $[18,27,28]$.

One way to study complexity is to model it as a mathematical system and simulate it over time. Dynamic simulation models (DSMs) of systems add insight beyond knowing how each of their parts works in statistical models by including interrelationships. They inform how variables change together in response to one another and other factors, unlike statistical models that tell how a variable responds to an input change, holding other inputs constant. DSMs usually aim to project what may happen to variables in the future, unlike statistical models that seek to explain variables based on data, typically one at a time [29]. No one, of course, knows the future. DSM projections depend on their input values (storyline) and, like all models, simplify reality.

Building on Virchow's idea of health as social, we take a system science approach to population health. Populations are complex systems, and examining their health can benefit from modeling it together with population size, migration, and the potential for conflict over time, taking account of the ecological impacts of climate change (EICC), social determinants of health, and other factors [24, 25, 28, 30,31]. Demand for such DSMs is rising among a broad range of stakeholders [28, 32].

A survey of theory-based empirical processes in critical domains provides a natural starting point for DSM design. The survey results, presented in the next section, paint a complex interconnected and interdisciplinary picture occasioned by inequalities in health, environmental health, and access to health care and environmental health services for immigrants compared to native hosts, especially for those coming from or migrating internally in developing countries. The associated complexity may explain why social science has not developed a DSM of the type we propose despite those calls and rising demand.

One challenge of modeling dynamic systems is the temptation to explain "too much." Thinking "too big" may create a model in which everything affects everything else, making it hard to understand anything; it is better to model some things as exogenous [33]. The 
climate migration-public health picture is complex and hard to model in one fell swoop, even after defining some factors as exogenous. We do not have a magic solution to address this interdisciplinary complexity alone, so we turn to one of the oldest tricks in the "book of modeler": start simple to get the ball rolling.

We aim to validate the feasibility and usefulness of a basic DSM intended to serve as a basis for identifying extensions to make it more realistic. Our model is a pilot, a computational proof-of-concept illustrating that we can and should do more to develop DSMs of climate migration and population health. It simplifies reality, but it is already rigorous, resulting in many variables and parameters. Our pilot model depicts people migrating each period and joining their brethren in a host area. The origin and destination sites can be in the same country or different countries. An origin has one group of residents, its population, and a host site has two groups, immigrants and native hosts. A group needs health care (HC) depending on its health problems (HP) and environmental health services (ES) depending on the non-EICC environmental health problems (EP) it faces (e.g., pollution, waste, toxic materials). A site may have EICC and conflict. The model computes composites of all intrastate conflict types per site, all HP pc, EP, HC, ES, $\mathrm{HC}$ quality, and ES quality types, in turn, per group; population per group; HC and ES capacities per site; and the number of migrants per period by the OD pair and their HP pc on arrival. These variables affect one another and respond to respective exogenous composites of EICC, HC barriers, and social, political, economic, natural, demographic, and geographic factors.

We simulate our pilot DSM for reasonable synthetic values since the literature does not measure its composites as such. The sizes of the obtained effects are thus likely inexact from a real-world viewpoint. However, their directions and dynamic patterns are plausible and, like the sizes, respond logically in sensitivity analyses. Our pilot DSM has conceptual validity since it integrates theory-based empirical mechanisms. It has plausibility, internal, and sensitivity validities since it delivers sensible results that agree with associated theories. It is thus valid enough for its stated intended use. We suggest modeling extensions to increase model realism and lay out a path on how to do that.

A fully validated DSM examining interrelationships between migration, population, public health, and armed conflict under climate change for given input values could suggest conditional answers to relevant questions. For example, how many migrants may come to a host area when certain EICC intensify in their origin site, other things the same? How healthy could they be on arrival? If a certain number arrives over a specified duration, how will the native-host health change? If EICC in their origin harm their health, what may be the health effects in their host area? What may be the effects if host authorities limit their access to $\mathrm{HC}$ and ES available for native hosts? Will the host's HC and ES systems suffice to address the total need as climate migrants arrive? Could armed conflict occur in the host area, and if so, what might be its HP, EP, HC, and ES impacts? Given the projected rise in global migration due to changes in EICC, demographic profiles, and other factors, as well as the current HP, EP, HC, and ES inequalities for internal immigrants in internal immigration hubs such as urban China and India, and international in almost all nations, developing such a DSM is more pertinent now than ever before.

\section{Methods}

Nascent public health research treats health outcomes observed for modern-day migrants as analogs for the future climate migrants. Empirical social science research separately studies essential domains in the context of modern-day migration. Surveying the associated results provides a logical starting point for DSM design. Our survey does not aim to contradict (or support) reported findings. We take them all at face value and merge their causal processes with system science principles in designing our DSM. The idea guiding our DSM design, in other words, is not to arbiter disagreements on the signs, sizes, and significance of observed effects but rather to inform possible impacts of different assumptions on the projected system behavior by setting the input values accordingly.

\section{Empirical social science research}

We start with empirical results on the factors of migration. We then discuss results for the roles of immigration and the ecological impacts of climate change (EICC) in conflict. Findings on exposures to EICC and other environmental health problems (EP), health care (HC) use, $\mathrm{HC}$ access, $\mathrm{HC}$ quality, and health problems (HP) in the context of immigrants provide the next anchors for our discussion. Finally, we examine the social determinants of health and the impacts of conflict on HP and EP. The overall research is too large to cover fully here. We summarize and cite examples.

\section{Migration}

A large empirical modeling literature explains migration. Results for permanent authorized international immigrants (PIMs) [34], authorized temporary international immigrants (TIMs) [35], unauthorized international immigrants [36], and internal-migrants [37] are quite similar. Migration rises with origin site factors such as poverty, joblessness, and conflict; opposite forces in a destination site; population size in each site; OD-pair 
proximity, amity, ease of entry, diaspora, and shared language; and the difficulty of moving elsewhere. Refugees and asylum-seekers migrate primarily due to conflict and repression in their origin site, but otherwise, follow suit [38].

New models find international migration rises with environmental changes of the type associated with EICC in sites of origin (rain decline [39], more frequent and intense extreme weather events [40], rain and heat anomalies [41], storms [42]), controlling for those other factors. Current data, as noted, say more people migrate internally than abroad, especially in the South. Results show more EP [43], extreme weather events [44], droughts [45], heat, and storms [46] in origins raise internal emigration. Still, there are more possibilities. Sufficiently large EICC-related impacts and financial losses can hinder the ability to migrate abroad, especially from developing nations [47].

The overall impact of conflict on migration also reflects competing forces. Studies generally find that conflict events in origins site increase emigration, as noted. However, logic and some findings suggest that severe enough conflict events can reduce the abilities to migrate and to cope in situ with EICC; the latter effect, in turn, can raise emigration from impacted regions or, if it is large enough, reduce the outflow [48].

Historically, epidemics contributed to migration from affected areas. The Black Death, e.g., led to migration in Europe and the Middle East. Newer cases include the migrations linked to the 1800s cholera and smallpox in Holland [49]), 2008-9 cholera in Zimbabwe [50], 2009 influenza in Mexico, 1994 plague in India, and 2002-3 SARS in China [51]. A recent statistical model finds epidemics promote emigration worldwide, controlling for other factors [52]. Research on the role of modern-day outbreaks in migration is emerging. Logically, there are more possibilities. Epidemics may have little effect on the current migration as they usually have remedies, and governments curtail mobility in response. They may also reduce the ability to move if they have no readily available cures or vaccines.

\section{Armed conflict}

Models find the risk of conflict rises with population and the prior conflict risk and level [53] [54], controlling for other factors (e.g., economic, political). New models find areas with more refugees and asylum-seekers are at higher risks of terror attacks [55] and civil wars [56], and with more foreign immigrants terror attacks [57] and interstate conflict [58]. Internal immigration contributes to civil strife [59, 60]. The International Panel on Climate Change finds EICC amplify conflict risk factors such as economic decline, ethnic tension, poverty, inequality, and grievance, especially in the South [3].
Newer models find more extreme weather events [61], temperature/rainfall anomalies [62], and droughts [60], and higher peak temperatures [63] raise civil conflict risk, controlling for other factors. States with less rainfall and stronger extreme weather events [64], more extreme weather events [65], and more variable rainfall [66] are at higher risk of interstate conflict.

Epidemics have long fueled armed collective violence. Examples include the Black Death peaking in the Middle East and Europe in the fourteenth century and recurring well into the 18th, cholera in Europe in the nineteenth century, plague in India (1896-1914), Spanish Flu in the United States (1918-20), HIV/AIDS in Zimbabwe in the 1990s and 2000s [67, 68], and Covid- 19 in Columbia, Yemen, Africa, and Ukraine as of 2020 [69]. Nascent models find epidemics fueled wars in China from 1470 to 1911, taking account of other factors [70]. Results show states with higher rates of vector-borne parasitic diseases [71] and more HIV/AIDS [72], and areas with more Ebola in West Africa [73] and Covid-19 in Burkina Faso, Libya, Mozambique [74] and India [75] have more conflict. In Africa, areas with high and low malaria rates are at a smaller risk of conflict than areas with moderate rates [76].

\section{Ecological impacts of climate change (EICC) and non-EICC environmental health problems (EP)}

Emerging research finds that areas with more SouthNorth immigrants are at higher flood risk and less flood defense, response, and aid, and slower recovery (Florida [77], Texas [78]). In contrast, high-status coastal areas attract the affluent, where the costs of risk mitigation are partly carried by the broader public [79]. Residential segregation, affordability, and real estate industry practices contribute to these patterns [78]. Other recent studies find areas with more South-North immigrants face more EP harmful for health, controlling for factors like income, production, and population. Studies usually ascribe this pattern to anti-immigrant bias in EP regulation, and immigrant weakness in not-in-my-backyard lobbying, and inability to find cleaner jobs and afford cleaner areas. Examples include exposure to pesticides [80], waste burners [81], industrial/auto emissions [82], fine-particle air pollution [83], and industrial toxins [84]. In China, rural-urban immigrants are more exposed than city natives to landfills, noise, emissions [85], and ground-ozone [86], and in Mexico to pesticides [87].

\section{Health care $(H C)$ access}

Internal immigrants access $\mathrm{HC}$ like locals except in nations linking it to a registered residence and making it hard to change status (e.g., China [88]). Migration abroad can improve $\mathrm{HC}$ access compared to that in the origin site. However, the rights of foreign immigrants for 
$\mathrm{HC}$ vary by country and are usually complex matters of law that go by immigrant features like type and agegroup. We summarize some conditions.

In the United States, e.g., arriving permanent authorized international immigrants (PIMs) and temporary authorized international immigrants (TIMs) access like citizens but wait five years for funded care if low income [89]. In Canada, new PIMs buy HC or private insurance for several months, then get access; TIMs get partial access [90]. In Australia, PIMs, and some TIMs (e.g., applicants for permanent stay, workers) get access [91]. In the European Union, PIMs and TIMs get full access in 10 states (e.g., Germany, France) and conditional (e.g., work permit) in 22 (e.g., Spain, Britain) [92]. Malaysia requires buying limited private insurance [93]. South Africa [94] and Thailand [93] give access, and Kenya charges more than nationals [95]. In Turkey, new PIMs buy $\mathrm{HC}$ or private insurance for eight months and then get access; TIMs get only emergency care (EC) [96] as do PIMs and TIMs in Russia [97].

Among signers of refugee treaties, the United States gives refugees funded $\mathrm{HC}$ up to eight months and then access [98], Australia gives access and free initial HC [99], and Canada partial up to a year and then full [100]. The European Union [101], Turkey [96], Kenya [95], and Russia [102] give access and South Africa basic HC [94]. Among non-signers, Malaysia bills more [103], and Thailand treats refugees like unauthorized international immigrants [104]. The United States, Britain [105], and Australia [106] may detain Asylum-seekers with limited HC. Those allowed to live in the community get access to $\mathrm{HC}$ in the United States [107] and partial access in Canada [100]. In the European Union, seven states give access (e.g., France), seven conditional access (e.g., stay in centers, Greece), seven partial (Sweden), ten partial and contingent (Portugal), and two only emergency care (Germany) [81]. Thailand and Malaysia give partial access [108]; South Africa rudimentary care [94]; Turkey access to asylum-seekers from the European Union, Turkey, and Syria, and partial access to others [109]; and Kenya bills more [95].

In Canada [90] and the United States [110], Unauthorized international immigrants get only emergency care with pay and, maybe, funded emergency care and open center $\mathrm{HC}$ if low income. Australia gives limited access [111]. Five European Union states give conditional access (France), three give partial (Italy), four give partial and conditional (Spain), eight give only emergency care (Germany). Seven give ad hoc emergency care (Britain), and six only paid emergency care (Norway) [92]. South Africa offers basic HC [94], and Russia limited access with pay [97]. Malaysia provides partial access with payment, Thailand partial and costlier access in the area of residence [93], Turkey only emergency care with pay [101], and Kenya only HC in open centers [95].
South-North immigrants may face more barriers to access, e.g., language, cost, limited info, red tape, and delay (United States [112], Canada [113], European Union [114], Scandinavia [115], Australia [116]). South-South foreign migrants may also face long travel for $\mathrm{HC}$, xenophobia, and claims they drain $\mathrm{HC}$ and bring disease (Kenya [95], Africa [117], Southeast Asia [108], South Africa $[94,118])$. Provider attitudes may stand in the way [119]. Canadian providers may be aloof toward SouthNorth immigrants, use racial slurs [120], and see them as finicky and substance abusers [121]. Portuguese may see them as violent [122]; Belgian wanton [123]; Norwegian different, Dutch difficult, and Swedish rude [124]. HC staff may also tell South-North unauthorized immigrants to pay upfront, reject them as regular patients, deny them care, and report them to the authorities (the North [125], European Union [126]). Providers in the United States may see them as spreading crime and drugs and raising cost and job losses for natives [127], and French as faking illness to be allowed to stay [128].

\section{Health care $(H C)$ use and provided quality}

Models compare $\mathrm{HC}$ use for natives and immigrants, usually South-North, using surveys or records in one country, controlling for, e.g., health, income, insurance, and age. Results show South-North immigrants in the United States generally use less HC than natives (emergency care [129], mental [130], primary care [131]). They tend to overuse emergency care for regular care and underuse other $\mathrm{HC}$ in countries that offer free and low-cost emergency care (Australia [132], Canada [133], France [134], European Union [135]). South-south foreign immigrants (South Africa [136], Russia [97], Malaysia [137]) and rural-urban internal immigrants follow suits (China [138], India [139]). Refugees and asylum-seekers tend to use more HC than natives (United States [112], Canada [140], Britain [141], Germany [142], European Union [143], Thailand, Kenya [144]). New models study the unmet need for $\mathrm{HC}$ (non-use when needed), controlling for those factors. Results show South-North immigrants are at higher odds of unmet need than natives (United States [145], Norway [146], Italy [147], Holland [148]).

Studies defined HC quality as the extent that the delivered $\mathrm{HC}$ is safe, scientific, warranted, patient-centered, efficient, and timely [149]. Statistical models of the type employed for $\mathrm{HC}$ use find that South-North immigrants in the United States are at higher risk of lower HC quality in general non-patient centered HC [150], and fewer offered cancer therapies [151]. Elsewhere, they are at higher risk of generic or flawed care in Spain [152], subpar maternal care in France [153] and other European Union states [154], and inadequate psychiatric care in Sweden and Canada [124]. Unauthorized international immigrants are at higher risk of being shifted to other 
providers in the European Union [155] and of not being slated for follow-ups in Denmark and Belgium [119]. Refugees and asylum-seekers are at higher risk for subpar psychiatric care in Switzerland [156] and suboptimal maternal care in Iran [157]. South-North immigrants are at higher risk for needless hospitalization (preventable with primary care) in Britain [158], United States and New Zealand [159], and Singapore [160], and extended hospital stay (compared to a mean by diagnosis and treatment) and unplanned hospital readmission (within 30 days after discharge) in Holland [161], controlling for those factors.

\section{Health problems (HP)}

European colonizers introduced new infectious diseases into native societies. The results were often catastrophic. Many studies examine immigration as a "health threat" and stress screening and isolation [162]. Current immigrants from the South are sometimes falsely blamed for spreading infectious diseases, though some South-North immigrants, especially refugees, asylum-seekers, come from places with disrupted HC [163]. Today, infectious diseases usually have remedies, and their effects in the North are relatively small [164]. Impacts are often more significant in the South, where HC systems are weaker [117].

Models examine health using surveys and records in one nation. Many find that authorized permanent and temporary South-North immigrants are healthier than natives upon arrival, controlling for $\mathrm{HC}$ and those factors. Examples include better blood pressure and birth outcomes in the United States [165]; health status in the United States, Australia, Britain, Canada [166], and the European Union [167]; mortality in Canada [168]; and mental health in Britain [169]). Reasons suggest ailing people may not migrate, ailing immigrants may return, developed countries screen South-North immigrant health for entry, and immigrants support each other $[170,171]$. The effect wanes over time in the host area due to immigrant alienation, poverty, assimilation stress, and unhealthy diet [171].

Others find similar or higher risk for these immigrants (chronic US, Australia, Canada [166]; perinatal US, European Union [170]; mental US, Australia, Canada, European Union [172]; ischemia, stroke European Union [173]; typical HP Sweden [174]; health status Switzerland [175]). Often holding unsafe, dirty, and manual jobs shunned by natives, they are at higher risk for injury, skin, respiratory, perinatal, mental, and musculoskeletal HP [176]. Children and elders often have HP (Canada [177], North [178]). Refugees and asylum-seekers face conflict and usually reside in crude camps on their way. They are at higher risk of MRSA (Holland [179]), tuberculosis (Germany [180]), oral HP (Australia, US, Canada, European Union [181]), perinatal and mental HP
(Australia [182, 183]), mental HP (United States [184]), and mental and digestive HP, diabetes, and orthopedic HP (Britain [185]). Detention of asylum-seekers and unauthorized international immigrants harms their mental health (Australia [186], Britain, Canada [187], United States [188]).

For the South, some models find rural-urban internal migrants in China are healthier than city dwellers (e.g., health status [189]); others do not (maternal/mental HP, infectious diseases [190], overall [191], child mental HP [192]). In India, such migrants are at higher risk for mental HP, infectious diseases, mother underweight, and child anemia and stunted growth [139]. South-South foreign immigrants are at higher risk of child mortality in South Africa [193] and Kenya [194], and Malaria, HIV/ AIDS, and tuberculosis in South Africa [117]. Refugees, asylum-seekers, and unauthorized foreign immigrants are at higher risk for mental HP in South Africa [194] and Nigeria [195]; mental HP [196] and infectious diseases [197] in Bangladesh; Hepatitis B in Iraq [198]; and physical trauma in Turkey [199].

\section{Social determinants of health}

Growing social science modeling research examines the impacts of social factors on group health measures such as life expectancy and specific HP's risk, usually for state or substate units. Results reveal the positive effects of income inequality on heart attack risk at the United States state level [200]; social spending on life expectancy in Canadian provinces [201]; medical technology on life expectancy in developed nations [202]; democracy and health and education expenditures on life expectancy in Asian states [203]; and air pollution on mortality in Chinese counties [204] and Californian areas [205]. Non-whiteness promotes premature birth in the United States [206], discrimination harms mental and cardiovascular health, and low socioeconomic status harms health [207]. Few models study migration. In the European Union, South-North immigrants in states with policies that exclude immigrants and foster assimilation are less healthy than those without such policies [208]. Pro health spending and equity policies in the European Union help natives more than immigrants (due to $\mathrm{HC}$ barriers) [209].

\section{Conflict impacts on $H P, H C$, and $E P$}

New studies find conflict harms health directly (e.g., injury, mental trauma, worsening existing HP) and indirectly (e.g., causing EP, damaging $\mathrm{HC}$, reducing food security). Children, women, the elderly, and relegated groups are at higher risk [210, 211]. Conflict disperses infectious diseases by moving carriers, crowding refugees, impeding eradication, and lowering immunity (e.g., France-Italy wars (the 1500s) syphilis; Napoleonic wars 
typhus; Crimean war (1854-6) dysentery; France-Prussia war (1870-1) smallpox; World War I influenza; Afghanistan war tuberculosis [67]). In the 2010s, it spread cholera in Africa and Yemen, yellow fever in Angola, infectious diseases in Syria, and polio in Afghanistan, Pakistan, Iraq, and Somalia [212, 213]. Nascent models find conflict raises the risk of leishmaniasis in the South [214], infant mortality and stunted child growth in Africa [215], HIV/AIDS Africa [216], and Ebola in Congo DR [217], controlling for other factors. Immigrants from conflict areas are at higher risk of mental HP than residents (Canada [218]). Conflict disrupts $\mathrm{HC}$ in Africa, and lowers the odds of birth in medical facilities [219], creates EP [220], and disrupts ES [221] (e.g., Iraq, Vietnam, the South [222]). Nascent models find similar results for EP [221, 223].

\section{Pilot model}

We join these results with system modeling. Time (t) moves from 0 in periods. The model computes stocks (totals by $\mathrm{t}$ ), flows (stock changes per period), and auxiliary variables. Its inputs are parameters, time series (scenarios), initial stocks, initial lagged variables, and controllers (tell whether to compute some variables or set them to given values, for flexibility). At the start of a simulation, the model assigns selected values to all its inputs. It then computes by period for the desired simulation duration.

The model simplifies reality in line with our stated plan to do so. It depicts a system with one origin and one destination and no inter-site conflict. The migration process ends within a period. The period size is one in unnamed units, and the variables are composites. The origin site has one population, and the destination has two, natives and immigrants, which do not intermix. We revisit these simplifying assumptions and evaluate them later.

The algorithm is general. The migration can be internal or international. Groups have individual stocks and flows of HP pc, EP, population, and variables for $\mathrm{HC} / \mathrm{ES}$ needs and provisions, qualities of provided $\mathrm{HC} /$ ES when needed, and barriers (legal and otherwise) to access $\mathrm{HC} / \mathrm{ES}$. Sites have individual variables for $\mathrm{HC} / \mathrm{ES}$ capacities (highest service volumes due to, e.g., existing $\mathrm{HC}$ providers/hospitals for $\mathrm{HC}$, and waste removal/treatment facilities for ES). HP pc rising above a threshold raises HC's need, and above a higher level, death. EP follows suits with levels for needing ES and increasing HP pc. A unit of provided HC/ES with a perfect quality reduces HP pc/EP by one. The exogenous variables (inputs) include EICC per site, HC/ES capacities without EICC and conflict per site, HC/ES qualities without these forces per group, HC/ES barriers per group, and integrated effects of non-EICC (TNE) factors such as social, economic, and political on computed variables.
One may present DSMs in several ways (e.g., equations, a diagram, in the main text, in an appendix). We show the math for sharpness, though, in truth, there is no perfect or standard way to show DSMs. Following the math may require careful reading as our DSM includes many equations, variables, and parameters. We hope that our approach of defining the variables and parameters when introduced and in a list available online in Additional file 1: Appendix under the title Supplementary Information at the end of the paper and devising informative notation rules would help.

Variable names use the form $X \_Y \_Z_{T}$. $X$ is o for origin, $\mathrm{d}$ destination, od pair, dn destination natives, and di destination immigrants. $\mathrm{Y}$ is a label; it ends with pc for per capita. $\mathrm{Z}$ is $\mathrm{s}$ for stocks, $\mathrm{f}$ for flows, $\mathrm{p}$ for parameters, a for auxiliaries, $x$ for exogenous variables, and tx for TNE effects. $T$ is $t$ in this period, $t+1$ the next, $t-1$ prior. Parameters exclude $\mathrm{T}$ and names shared by groups/sites $\mathrm{X}$. Flows, rates, TNE effects, and some random draws can take any value. Other variables vary in ranges or are $\geq 0$. We use five functions. $R(x, p)$ depends on input $x \geq 0$ and parameter $\mathrm{p}: \mathrm{R}=0$ for $0 \leq \mathrm{x} \leq \mathrm{p}$ and rises with $\mathrm{x}$ for $\mathrm{x}>\mathrm{p}$. $R F\left(x, p_{1}, p_{m}, p_{2}, f_{m}\right)$ depends on $x \geq 0$ and parameters $0 \leq$ $\mathrm{p}_{1} \leq \mathrm{p}_{\mathrm{m}} \leq \mathrm{p}_{2}$ and $\mathrm{f}_{\mathrm{m}} \geq 0$ : RF $=0$ for $0 \leq \mathrm{x} \leq \mathrm{p} 1$; rises with $\mathrm{x}$ for $\mathrm{p} 1 \leq \mathrm{x}<\mathrm{p}_{\mathrm{m}} ;=\mathrm{f}_{\mathrm{m}}$ for $\mathrm{x}=\mathrm{p}_{\mathrm{m}}$; falls above 0 as $\mathrm{x}$ rises from $\mathrm{p}_{\mathrm{m}}$ to $\mathrm{p}_{2} ;=0$ for $\mathrm{x}=\mathrm{p}_{2}$; and falls below 0 as $\mathrm{x}$ rises above $\mathrm{p}_{2}$. R/RF give zero if all their parameters are zero. We name them serially (their values differ by equation/input). $\operatorname{MAX}(\mathrm{x}, \mathrm{y}) / \operatorname{MIN}(\mathrm{x}, \mathrm{y})$ give the largest/smallest among $x$ and $y$. $R D$ (pd, ps) randomly draws a number from probability distribution pd. with a parameter set ps.

We present the equations for time $t$ in the order of computation. To simplify, we do not show tests of controllers (if _ $\mathrm{c}=1, \mathrm{x}=$ scenario; else, compute $\mathrm{x}$ ), zero population (if pop_s $=0, x p c=0$ ), and range (if $x>1$, $\mathrm{x}=1$ ), and parameters of the $\mathrm{R} / \mathrm{RF}$ functions, but they are understood.

\section{Conflict}

The model compares a computed conflict risk (likelihood) to a threshold randomly drawn from a probability distribution defined on the range 0 to 1 . If the risk tops that threshold, the model computes conflict intensity; else, it sets the conflict intensity to 0 (none). We use a uniform distribution, assuming a site has a neutral conflict proneness (any threshold is equally likely to be chosen). For a conflict-prone site, one would use a right-skewed distribution (tail on the right), making it easier for the computed risk to top the threshold, and vice versa for peace-prone.

The risk of conflict in the origin site $\left(o_{-}\right.$cr_a) rises when the site's population stock (o_pop_s) and the prior conflict risk ( $\left.\mathrm{o}_{-} \mathrm{Cr} \mathrm{a}_{-} \mathrm{a}_{-1}\right)$ top respective thresholds in $\mathrm{R}$ functions. The impacts of the EICC and previous conflict intensity follow RF functions (first increase and then 
decline due to, e.g., damage to arms and the ability to fight). The effect of HP pc also follows an RF function (rises and then falls as people become less able to fight due to, e.g., morbidity and, for infectious diseases like cholera, high exposure promoting immunity and thus reducing the pro-conflict effect [76]). The TNE effect follows scenario o_cr_tx. Not shown, the model keeps the computed conflict risk between 0 and 1 (as it is a probability).

1. $\quad$ o_cr_a $\mathbf{a}_{\mathbf{t}}=\mathbf{R}_{\mathbf{1}}\left(\mathbf{o} \_\mathbf{p o p} \_\mathbf{s}_{\mathbf{t}}\right)+\mathbf{R}_{\mathbf{2}}\left(\mathbf{o} \_\mathbf{c r} \_\mathbf{a}_{\mathbf{t}-\mathbf{1}}\right)$

$+R F_{1}\left(o_{-}\right.$eicc_ $\left.x_{t}\right)+R F_{2}\left(o_{-}\right.$ci_ $\left.a_{t-1}\right)+R F_{3}$

$\left(\right.$ o_hppc_s $\left.\mathbf{s}_{\mathbf{t}}\right)+$ o_cr_t $\mathbf{x}_{\mathbf{t}}$

The model randomly draws a risk threshold from a uniform distribution, compares it to o_cr_a, and computes the conflict intensity (o_ci_a), or sets it to zero, accordingly.

2. if $o_{-}$cr_ $\mathbf{a}_{\mathbf{t}} \leq \mathrm{RD}$ (uniform, $\left.\mathbf{0}, \mathbf{1}\right)$ : o_ci_a $a_{t}=0$

3. if $\mathbf{o}_{-} \mathbf{c r} \mathbf{a}_{\mathbf{t}}>\mathbf{R D}$ (uniform, $\left.\mathbf{0}, \mathbf{1}\right)$ : o_ci_a $a_{t}=R_{3}\left(o \_p o p \_s s_{t}\right)+R F_{4}\left(o \_e i c c \_x_{t}\right)+$ $R_{5}\left(o_{-} c i \_a_{t-1}\right)+R F_{6}\left(o \_h p p c \_s_{t}\right)+o_{-} c i \_t x_{t}$

Conflict risk in the destination site $\left(d_{-}\right.$cr_a $)$depends on the sizes of the immigrant and native populations (di_pop_s, dn_pop_s), their HP pc stocks (di_hppc_s, dn_hppc_s), and site factors. The model compares the computed risk to a random risk threshold and sets the conflict intensity (d_ci_a) accordingly.

4. $\mathbf{d} \_c r \_a_{\mathbf{t}}=\mathbf{R}_{\mathbf{4}}\left(\mathbf{d i} \_\right.$pop $\left.\_\mathbf{s}_{\mathbf{t}}\right)+\mathbf{R}_{\mathbf{5}}\left(\mathbf{d n} \_\right.$pop_s $\left.\mathbf{s}_{\mathbf{t}}\right)+$ $\mathbf{R}_{\mathbf{6}}\left(\mathbf{d}_{-} \mathbf{c r}_{-} \mathbf{a}_{\mathbf{t}-\mathbf{1}}\right)+\mathbf{R F}_{\mathbf{7}}\left(\mathbf{d} \_\mathbf{e i c c} \mathbf{x}_{\mathbf{t}}\right)+\mathbf{R F}_{\mathbf{8}}\left(\mathbf{d} \mathbf{d}_{-} \mathbf{c i}_{-} \mathbf{a}_{\mathbf{t}-\mathbf{1}}\right)+$

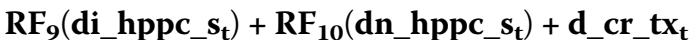

5. if $\mathbf{d}_{-}$cr_ $\mathbf{a}_{\mathbf{t}} \leq \mathbf{R D}$ (uniform, $\left.\mathbf{0 , 1} \mathbf{1}\right)$ : d_ci_a $a_{\mathbf{t}}=\mathbf{0}$

6. if $d_{-} c_{-} a_{t}>R D$ (uniform, 0,1$)$ :

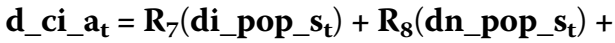
$R_{11}\left(d_{-}\right.$eicc_ $\left.x_{t}\right)+R_{12}\left(d \_c i \_a_{t-1}\right)+$ $R_{13}\left(d i \_h p p c \_s s_{t}\right)+R F_{14}\left(d n \_h p p c \_s_{t}\right)+d \_c i \_t x_{t}$

\section{Arrivals \& their HP pc:}

A sum of three effects gives the number of immigrants from the origin to the destination in time $t$ (od_nm_a). An OD effect tracks TNE scenario od nm_tx. An origin effect (o_nm_a) depends on TNE scenario o_nm_tx, rises as the population rises above a threshold, and rises as the HP pc stock, EP stocks, conflict, and EICC increase and then falls as these four forces continue to increase above their distinct migration obstacle levels, in turn. A destination's effect (d_nm_a) depends on TNE scenario d_nm_tx, increases as the immigrant and native populations rise above respective thresholds, and falls as their HP pc stock (di_hppc_s, dn_hppc_s), the EP stocks they face (di_ep_s, dn_ep_s), and EICC and conflict in the destination rise above respective thresholds.

7. $\quad \mathbf{o} \_\mathbf{n m} \_\mathbf{a}_{\mathbf{t}}=\mathbf{R}_{\mathbf{9}}\left(\mathbf{o} \_\mathbf{p o p} \_\mathbf{s}_{\mathbf{t}}\right)+\mathbf{R F} \mathbf{F}_{\mathbf{1 5}}\left(\mathbf{o} \_\mathbf{h p p c} \_\mathbf{s}_{\mathbf{t}}\right)+$

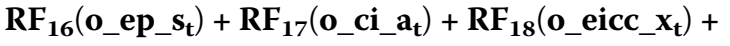
o_nm_t $x_{t}$

8. $\quad \mathbf{d} \_n \mathbf{n m}_{-} \mathbf{a}_{\mathbf{t}}=\mathbf{R}_{\mathbf{1 0}}\left(\mathbf{d i} \_\mathbf{p o p} \_\mathbf{s}_{\mathbf{t}}\right)+\mathbf{R}_{\mathbf{1 1}}\left(\mathbf{d n} \_\mathbf{p o p} \_\mathbf{s}_{\mathbf{t}}\right)-$ $\mathbf{R}_{12}\left(\right.$ di_hppc_s $\left.s_{t}\right)-R_{13}\left(d n \_h p p c \_s_{t}\right)-$ $\mathbf{R}_{14}\left(\mathbf{d i} \_\mathbf{e p} \_\mathbf{s}_{\mathbf{t}}\right)-\mathbf{R}_{15}\left(\mathbf{d n} \_\mathbf{e p} \mathbf{s}_{\mathbf{t}}\right)-\mathbf{R}_{16}\left(\mathbf{d} \_\mathbf{c i} \_\mathbf{a}_{\mathbf{t}}\right)-$ $R_{17}\left(d \_\right.$deicc_ $\left.x_{t}\right)+d \_n m_{-} x_{t}$

9. od_nm $\_a_{t}=0 \_n m \_a_{t}+d \_n m \_a_{t}+o d \_n m \_t x_{t}$

The HP pc of the immigrants upon arrival to the destination site (od_imhppc_a) reflects their origin's HP pc stock, and scenario od_nmhppc_x for the OD emigrant to origin HP pc ratio (value $=1$ means emigrants are as healthy as origin people are, $<1$ healthier, and $>1$ less healthy). This scenario captures emigrant self-selection by health (emigrants may be in better shape than others in the origin site, as migration is taxing, or less healthy and seek better $\mathrm{HC}$ ) and the health change during the migration.

\section{0. od_imhppc $\_a_{t}=0 \_h p p c \_s_{t} *$ od $\_n m h p p c \_x_{t}$}

\section{Origin health problems (HP) per capita (pc) flow:}

People need HC to the extent their HP pc stock tops threshold hchppc_p: MAX $\left(o_{-}\right.$hppc $\left.\_s_{t}-h c h p p c \_p, 0\right)$. HC need pc faces barriers (scenario o_hcb_x), which vary from 0 (none) to 1 (no access). The total needed $\mathrm{HC}$ for provision (o_tnhcfp_a) rises with the need and population and falls due to barriers.

\section{1. o_tnhcfp_a $a_{t}=\operatorname{MAX}\left(\mathbf{o} \_h p p c \_s_{\mathbf{t}}-\mathbf{h c h p p c} \_\mathbf{p}, \mathbf{0}\right)$ $*\left(\mathbf{1}-\mathbf{0} \_\right.$hcb_ $\left.\mathbf{X}_{\mathbf{t}}\right) * \mathbf{0} \_\mathbf{p o p} \_\mathbf{S}_{\mathbf{t}}$}

HC quality (o_hcq_a) tracks scenario o_hcq_x with entries from 0 (futile) to 1 (perfect) for a case without conflict and EICC. It falls as conflict and EICC rise above respective thresholds for causing damage.

\section{2. o_hcq_a $\mathbf{a}_{\mathbf{t}}=\mathbf{o} \_$hcq_ $\mathbf{x}_{\mathbf{t}}-\mathbf{R}_{\mathbf{1 8}}\left(\mathbf{o} \_\mathbf{c i} \_\mathbf{a}_{\mathbf{t}}\right)-$ $R_{19}\left(0 \_\right.$eicc_ $\left.x_{t}\right)$}

HC capacity follows scenario o_hcc_x for a case without conflict and EICC and declines as conflict and EICC increase above thresholds for causing damage, in turn.

$$
\begin{aligned}
& \text { 13. o_hcc_a } \mathbf{a}_{\mathbf{t}}=\mathbf{o} \_\mathbf{h c c} \_\mathbf{x}_{\mathbf{t}}-\mathbf{R}_{\mathbf{2 0}}\left(\mathbf{o} \_\mathbf{c i} \_\mathbf{a}_{\mathbf{t}}\right)- \\
& \mathbf{R}_{\mathbf{2 1}}\left(\mathbf{o} \_ \text {eicc } \_\mathbf{x}_{\mathbf{t}}\right)
\end{aligned}
$$


If the total need for provision (TNFP) of $\mathrm{HC}$ is below the HC capacity, the model provides the needed HC. Otherwise, it delivers the $\mathrm{HC}$ capacity itself. The HP pc flow impact of $\mathrm{HC}$ provision (o_phchppc_a) accounts for HC quality.

\section{4. o_phchppc_a $a_{t}=\operatorname{MIN}\left(\right.$ o_tnhcfp_a,$\quad$ o_hcc_a $\left.a_{t}\right) /$ o_pop_s $s_{t} *$ o_hcq_a}

The origin's HP pc stock rises if the emigrant group is healthier than a typical origin person, and vice versa. The linked impact on the HP pc flow (o_emhppc_a) is: ${ }^{2}$

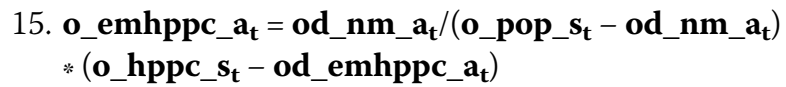

Health may change by chance. Densities of HP data tend to be large around some value and steadily fall away from it in either direction [224]. Probability distributions are usually closer to normal in healthy people than in sick [225] and may vary by HP type. ${ }^{3}$ Assuming people tend to be healthy, the model randomly draws the health impact of chance from a normal distribution with mean 0 and variance vhppc_p. Models assuming otherwise or disaggregating HP by type or level may use other distributions. Natural wear \& tear (wthppc_p) raises HP pc, and selfhealing (shhppc_p) lowers it. The EP stock facing the population (o_ep_s), conflict, and EICC raise HP pc as they rise above respective thresholds. A TNE impact on the HP pc flow tracks scenario o_hppc_tx.

The following equation joins the contributions to get the origin's HP pc flow (o_hppc_f):

\section{6. o_hppc_f $f_{t}=\mathbf{w t h p p c} \_p+\mathbf{R}_{22}\left(\mathbf{o} \_ \text {ep_s }\right)_{\mathbf{t}}+$ $\mathbf{R}_{23}\left(\mathbf{o} \_c i \_a_{t}\right)+R_{24}\left(0 \_e i c c \_a_{t}\right)+o \_e m h p p c \_a_{t}+$ RD(Normal, 0, vhppc_p) - shhppc_p - o_phchppc_a $a_{t}+$ o_hppc_t $x_{t}$}

\section{Origin environmental health problems excluding EICC (EP) flow:}

The expression MAX $\left(o_{-}\right.$ep _ $s_{t}-$ esep population's ES need (the extent the EP stock it faces tops threshold esep_p). ES need faces barriers (scenario o_esb_x), which vary from 0 (none) to 1 (no access). The total ES need for provision (o tnesfp_a) is:

\footnotetext{
${ }^{2}$ The departing HP is od_emhppc $a_{t} *$ od $n_{-} m_{-} a_{t}$. The origin's total $\mathrm{HP}$ is $\mathrm{o}_{-} \mathrm{hppc} \_\mathrm{s}_{\mathrm{t}} * \mathrm{O}_{-}$pop $\mathrm{s}_{\mathrm{t}}$. Ceteris paribus, the origin's HP pc stock in $t+1$ is o $o_{-} h p p c_{-} s_{t+1}=\left(o_{-} h p p c_{-} s_{t} * o_{-} p o p \_s_{t}-o d\right.$ emhppc _ $\left.a_{t} * o_{-} n m_{-} a_{t}\right) /\left(o_{-}\right.$pop $\left.s_{t}-o d_{-} n m_{-} a_{t}\right)$. Subtracting o hppc _ $\mathrm{s}_{\mathrm{t}}$ from both sides gives (14).

${ }^{3}$ For example, hemoglobin, body temperature [226], blood pressure, pulse rate, BMI, diabetes diagnosis age [227], total cholesterol [224], iron, glucose [225], are typically roughly normally distributed. Prostate PSA [228], homocysteine, paranoia [229], cancer clusters [224], and triglycerides [225] are not.
}

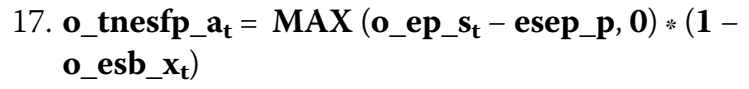

ES quality in the origin (o_esq_a) varies from 0 (futile) to 1 (perfect). It tracks scenario o_hcq_x with entries from 0 to 1 when there is no conflict, and EICC and falls as conflict and EICC rise above respective thresholds for causing damage.

$$
\begin{aligned}
& \text { 18. o_esq_a } \mathbf{a}_{\mathbf{t}}=\mathbf{o} \_ \text {esq_ } \mathbf{x}_{\mathbf{t}}-\mathbf{R}_{25}\left(\mathbf{o} \_c i \_\mathbf{a}_{\mathbf{t}}\right)- \\
& \mathbf{R}_{\mathbf{2 6}}\left(\mathbf{o} \_ \text {eicc } \_\mathbf{x}_{\mathbf{t}}\right)
\end{aligned}
$$

ES Capacity follows scenario o_esc_x in the absences of conflict and EICC and declines as conflict and EICC rise above respective thresholds for causing damage.

$$
\text { 19. o_esc } \_a_{\mathbf{t}}=\mathbf{o} \_ \text {esc } \_\mathbf{x}_{\mathbf{t}}-\mathbf{R}_{27}\left(\mathbf{o} \_c i \_\mathbf{a}_{\mathbf{t}}\right)-\mathbf{R}_{28}\left(\mathbf{o} \_ \text {eicc } \_\mathbf{x}_{\mathbf{t}}\right)
$$

If the ES capacity suffices, ES provision equals the total need for provision (TNFP) of ES; else, ES provision equals the ES capacity. The EP flow impact of ES provision (o_tpesep_a) is given by:

\section{0. o_tpesep_a $a_{t}=$ MIN $\left(o_{-} \_t n e s f p \_a_{t}, o_{-}\right.$esc $\left.\_a_{t}\right) *$ o_esq_a $a_{t}$}

An individual creates o_ieppc_p EP per period (e.g., bio waste, other waste, energy use pollution). Emigration cuts total creation. The flow impact is o ieppc $\mathrm{o}_{-} *\left(\mathrm{o}_{-}\right.$ pop_s $s_{t}-$ od_nm_a $\left.a_{t}\right)$. EP decays (e.g., breaks down, dissipates) at the rate o_decrep_p. The EP impacts of conflict and EICC rise as creation and ES damage offset harm to creators and then falls as the effects reverse. The TNE impact is o_ep_tx.

The following equation adds the impacts to get the EP flow in the origin site (o_ep_f).

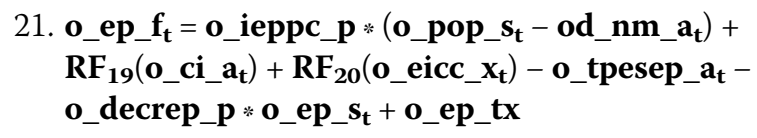

\section{Origin population flow:}

Parameter o_netbr_p gives the origin population's natural net birth rate (birth rate minus death rate). The population growth rate depends on a TNE impact (o popgr_tx) and falls due to emigration, and when the HP pc stock exceeds its death threshold. The HP pc death level tops that for $\mathrm{HC}$ need. The next equation gives the population flow (o_pop_f).

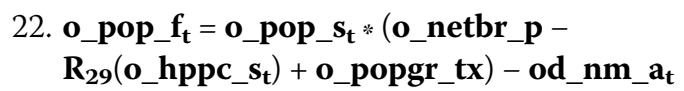


Destination health problems (HP) per capita ( $p c$ ) flows:

Groups need HC pc when their HP pc stock (di_hppc_s immigrants, dn_hppc_s native hosts) top threshold hchppc _ p. They face HC barriers di_hcb_x and $\mathrm{dn}_{-}$ hcb_x, in turn, which vary from 0 (none) to 1 (no access). The needed $\mathrm{HC}$ for the provision by group (di tnhcfp_a, dn_tnhcfp_a) and the total HC need for provision (d_tnhcfp_a) take account of the barriers to $\mathrm{HC}$ access and the population size by the group. The barrier scenarios by the group can capture varied cases. For example, a case with immigrants having better access to $\mathrm{HC}$ in the destination site than in their origin has higher barrier scenario values for the origin site than for the immigrants below.

23. di_tnhcfp_a $a_{t}=$ MAX (di_hppc_s $\left.s_{t}-h c h p p c \_p, 0\right)$ $*\left(1-d i \_h c b \_x_{t}\right) * d i \_p o p \_s$

24. dn_tnhcfp_a $a_{t}=$ MAX $\left(\mathbf{d n} \_h p p c \_s_{t}-h c h p p c \_p, 0\right)$ $*\left(1-d n \_h c b \_x_{t}\right) * d n \_p o p \_s s_{t}$

25. d_tnhcfp_a $a_{t}=d i \_t n h c f p \_a_{t}+d n \_t n h c f p \_a_{t}$

HC quality by group (di_hcq_a, dn_hcq_a) varies from 0 (futile) to 1 (perfect). It tracks scenarios di_hcq_x and dn_hcq_x, in turn, without conflict and EICC, and it falls when these forces rise above respective damage levels.

26. di_hcq_a $a_{t}=$ di_hcq_ $x_{t}-R_{30}\left(d \_c i \_a_{t}\right)-$ $R_{31}\left(d \_\right.$eicc_ $\left.x_{t}\right)$

27. dn_hcq_a $a_{t}=d n \_h c q \_x_{t}-R_{32}\left(d \_c i \_a_{t}\right)-$ $\mathbf{R}_{33}\left(\mathbf{d} \_\right.$eicc_ $\left.\mathbf{x}_{\mathbf{t}}\right)$

HC capacity (d_hcc_a) follows scenario d_hcc_x in the absence of EICC and conflict and decline when conflict and EICC exceed damage levels, in turn.

28. d_hcc $\_a_{\mathbf{t}}=\mathbf{d} \_h c c \_x_{\mathbf{t}}-\mathbf{R}_{\mathbf{3 4}}\left(\mathbf{d} \_c i \_\mathbf{a}_{\mathbf{t}}\right)-$ $\mathbf{R}_{35}\left(\mathbf{d} \_\right.$eicc_ $\left.\mathbf{x}_{\mathrm{t}}\right)$

Next, suppose the HC capacity in the destination site suffices for providing the TNFP of $\mathrm{HC}$ need in the area (d_tnhcfp_a). In this case, the provided HC per capita by the group (di_phcpc_a, dn_phcpc_a) equals the per capita need for provision.

\section{9. if d_tnhcfp_a $\mathbf{a}_{\mathbf{t}} \leq \mathbf{d} \_$hcc_ $\mathbf{a}_{\mathbf{t}}$ :}

di_phcpc_a $a_{t}=$ di_tnhcfp_a $a_{t} /$ di_pop_s $s_{t}$

dn_phcpc $\_a_{t}=d n_{-} \_$tnhcfp_a $a_{t} / d n_{\text {_pop_s }} s_{t}$

The model divides $\mathrm{HC}$ capacity falling short of the total need for provision (TNFP) of HC in the host area to the groups. In principle, there is more than one way to do it. The model offers two courses (one may add more if so desired). If scenario d_divhcc $\_x=1$ at $t$, the model divides the HC capacity by the groups' shares in the TNFP of HC.
30. if (d_tnhcfp_a $\left.a_{t}>d \_h c c \_a_{t}\right)$ and (d_divhcc $\left.\_x_{t}=1\right)$ : di_phcpc $\_a_{t}=\left(\right.$ di_tnhcfp_a $\left.a_{t} / d \_t n h c f p \_a_{t}\right)$ * d_hcc_at $/$ di_pop_s $s_{t}$ dn_phcpc $\_a_{t}=\left(d n \_t n h c f p \_a_{t} / d \_t n h c f p \_a_{t}\right) *$ d_hcc $a_{t} / d n$ pop_s $s_{t}$

If d_divhcc_x $=2$, groups get scenario shares (di hccsha_x, dn_hccsha_x) of the capacity.

31. if $\left(\mathbf{d}_{-}\right.$tnhcfp_a $\mathbf{a}_{\mathbf{t}}>\mathbf{d} \_$hcc $\left.\mathbf{a}_{\mathbf{t}}\right)$ and $\left(\mathbf{d}_{\_}\right.$divhcc $\left.\boldsymbol{x}_{\mathbf{t}}=2\right)$ : di_tphc_a $a_{t}=$ di_hccsha_ $x_{t} * d \_h c c \_a_{t} / d_{1}$ dipop_s $_{t}$

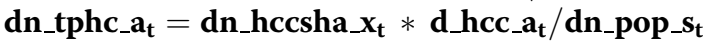

The HP pc flow impacts of the provided HC (di phchppc_a, dn_phchppc_a) take account of HC quality:

\section{2. di_phchppc $\_a_{t}=d i \_p h c p c \_a_{t} * d i \_h c q \_a_{t}$}

33. dn_phchppc $\_a_{t}=d n \_p h c p c \_a_{t} * d n \_h c q \_a_{t}$

The arrivals' HP pc (od_imhppc_a) impact on the immigrant HP pc flow (di_imhppc_a) is derived like for the origin. Since people join, it is negative when the arrivals are healthier than immigrants.

\section{4. di_imhppc $\_a_{t}=o d \_n m \_a_{t} /\left(d i \_p o p \_s t+\right.$ od_nm_a $\left.a_{t}\right) *\left(o d \_i m h p p c \_a_{t}-d i \_h p p c \_s_{t}\right)$}

Natural wear \& tear (wthppc_p) raises HP pc and selfhealing (shhppc_p) lowers it. EP, EICC, and conflict rising above thresholds, in turn, raise HP. A share of the immigrants' HP pc (dn_dihppc_p) spills over to affect the natives' HP pc (including the effect of countermeasures) due to, e.g., infectious diseases and copying habits that impact health (e.g., smoking, diet, exercise). The comparable native spillover share is di_dnhppc_p. TNE impacts follow scenarios di_hppcf_tx and dn_hppcf_tx. HP pc impacts of chance by the group are drawn from a normal distribution with mean 0 and variance vhppc_p, assuming people tend to be healthy. Model variants discerning HP by type or examine cases in which some populations are at high risk of HP (e.g., refugees and asylum-seekers, elderly) would use skewed distributions, as noted.

Next, the model computes the immigrants' and natives' HP pc flows (di_hppc_f, dn_hppc_f).

35. $\mathbf{d i} \_h p p c \_f_{\mathbf{t}}=$ wthppc $\_\mathbf{p}-\mathbf{s h h p p c} \_\mathbf{p}+$ $\mathbf{R}_{36}\left(\mathbf{d i} \_\mathbf{e p} \_\mathbf{s}_{\mathbf{t}}\right)+\mathbf{R}_{37}\left(\mathbf{d} \_\right.$eicc $\left.\mathbf{x}_{\mathbf{t}}\right)+\mathbf{R}_{38}\left(\mathbf{d} \_\mathbf{c i} \mathbf{a}_{\mathbf{t}}\right)+$ RD $($ Normal, 0 , vhppc_p) + di_dnhppc_p * dn_hppc_s $s_{t}-d i \_p h c h p p c \_a_{t}+d i \_i m h p p c \_a_{t}+$ di_hppcf_t $x_{t}$

36. $\mathbf{d n} \_h \mathbf{h p p} \_\mathbf{f}_{\mathbf{t}}=$ wthppc $\_\mathbf{p}-\mathbf{s h h p p c} \_\mathbf{p}+$ $\mathbf{R}_{39}\left(\mathbf{d n} \_\mathbf{e p} \_\mathbf{s}_{\mathbf{t}}\right)+\mathbf{R}_{40}\left(\mathbf{d} \_\right.$eicc_ $\left.\mathbf{x}_{\mathbf{t}}\right)+\mathbf{R}_{\mathbf{4 1}}\left(\mathbf{d} \_\mathbf{c i} \_\mathbf{a}_{\mathbf{t}}\right)+$ RD(Normal, 0, vhppc_p) + dn_dihppc_p * di_hppc_s $s_{t}-d n \_p h c h p p c \_a_{t}+d n \_h p p c f \_t x_{t}$ 


\section{Destination environmental health problems excluding EICC} (EP) flows:

People need ES when the EP stock they face rises above a limit. MAX (di_ep_s - esep_p, 0) gives the ES needed by the immigrants, and MAX (dn_ep_s - esep_p, 0) by the native hosts, where esep_p is the EP threshold for ES need. The groups' ES barriers (di_esb_x, dn_esb_x) vary from 0 (none) to one (no access). The needed ES for provision by the group (di_tnesfp_a, dn_tnesfp_a) and site (d_tnesfp_a) are given by:

37. di_tnesfp_a $a_{t}=\operatorname{MAX}\left(\right.$ di_ep_s $s_{t}-$ esep_p, 0$) *(1-$ di_esb_ $\left.x_{t}\right) *$ di_pop_s $s_{t}$

38. dn_tnesfp_a $a_{t}=$ MAX $\left(d n \_e p \_s-s_{t}-\right.$ esep_p, $\left.\mathbf{0}\right) *(1-$ $\left.d n \_e s b \_x_{t}\right) * d n \_p o p \_s_{t}$

39. d_tnesfp_a $a_{t}=d i \_t n e s f p \_a_{t}+d n \_t n e s f p_{-} a_{t}$

Without conflict and EICC in the host area, ES quality by group (di_esq_a, dn_esq_a), which varies from 0 to 1 , follows scenario (di_esq_x, dn_esq_x). Otherwise, it falls when conflict and EICC rise above harm levels, in turn. ES capacity (d_esc_a) follows suits with scenario d_esc_x for no EICC and conflict.

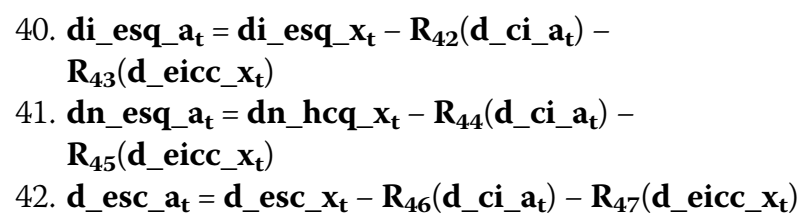

If the site's ES capacity (d_esc_a) suffices for the TNFP of ES (d_tnesfp_a), the ES provision by group (di_tpes_a, dn_tpes_a) equals the group's needed ES for provision (di_tnesfp_a, dn_tnesfp_a).

\section{3. if d_tnesfp_a $a_{t} \leq$ d_esc_a $a_{\mathbf{t}}$ : di_tpes_a $a_{t}=$ di_tnesfp_a $a_{t}$ dn_tpes_a $a_{t}=$ dn_tnesfp_ $a_{t}$}

If the ES capacity does not suffice for the TNFP of ES, and scenario d_divesc_ $x=1$ at $t$, groups get their shares in the overall need out of the ES capacity; if d_divesc_ $x$ $=2$, the immigrants get scenario share di_escsha_x of the ES capacity, and the native hosts share dn_escsha_x.

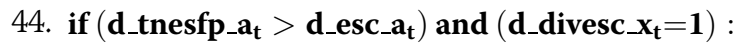
di_tpes_a $a_{t}=$ di_tnesfp_a $a_{t} / d_{-}$tnesfp_a $a_{t} *$ d_esc_a $a_{t}$ dn_tpes_a $a_{t}=$ dn_tnesfp_a $a_{t} / d_{-}$tnesfp_a $a_{t} * d_{-}$esc_ $a_{t}$

45. if $\left(\mathbf{d}_{-}\right.$tnesfp_a $\mathbf{a}_{\mathbf{t}}>\mathbf{d}_{-}$esc $\left.\_\mathbf{a}_{\mathbf{t}}\right)$ and $\left(\mathbf{d}_{-}\right.$divesc $\left.\_\boldsymbol{x}_{\mathbf{t}}=2\right)$ : di_tphc $\_a_{t}=$ di_escsha $x_{t} * d d_{-}$esc $\_a_{t}$ dn_tphc $\_a_{t}=d n \_$escsha $\_x_{t} * d \_$esc $\_a_{t}$
The EP flow impacts of the provided ES by group (di pesep_a, dn_pesep_a) are given by:

46. di_pesep_a $a_{t}=d i \_t p e s \_a_{t} * d i \_e s q \_a_{t}$

47. dn_pesep_a $a_{t}=d n \_t p e s \_a_{t} * d i \_e s q \_a_{t}$

Individuals create d_ieppc_p EP per period. The total creation is $d_{-}$ieppc $p_{-} * d_{d_{-}} p o p_{-} s_{t}+o d_{-} n m_{-}$ $a_{t}$ ) for the immigrants and $d_{-}$ieppc $p_{-} * d_{n}$ pop _ $s_{t}$ for the natives. Share dn_diep_p of the immigrants' EP spills over to raise the EP facing the natives (e.g., due to wind, dumping). As a result, the immigrants' EP stock declines. The natives' spillover share is di dnep_p. The EP changes are di dnep $_{-} \mathrm{p} * \mathrm{dn}_{-} \mathrm{ep}_{-} \mathrm{s}_{\mathrm{t}}$ $-\mathrm{dn}_{-}$diep $\mathrm{p}_{\mathrm{p}} * \mathrm{di}_{-} \mathrm{ep}_{-} \mathrm{s}_{\mathrm{t}}$ for the immigrants, and $\mathrm{dn}{ }_{-}$diep _ $\mathrm{p} * \mathrm{di}_{-} \mathrm{ep}_{-} \mathrm{s}_{\mathrm{t}}-\mathrm{di}_{-} \mathrm{dnep} \mathrm{p}_{-} \mathrm{p} * \mathrm{dn}_{-} \mathrm{ep}_{-} \mathrm{s}_{\mathrm{t}}$ for the natives. EP stocks decay at the rate d_decrep_p. The EP effects of conflict and EICC track RF functions and the TNE effects scenarios (di_ep_tx, dn ep_tx).

The next two equations compute the EP flows for the immigrants and natives (di_ep_f, (dn_ep_f):

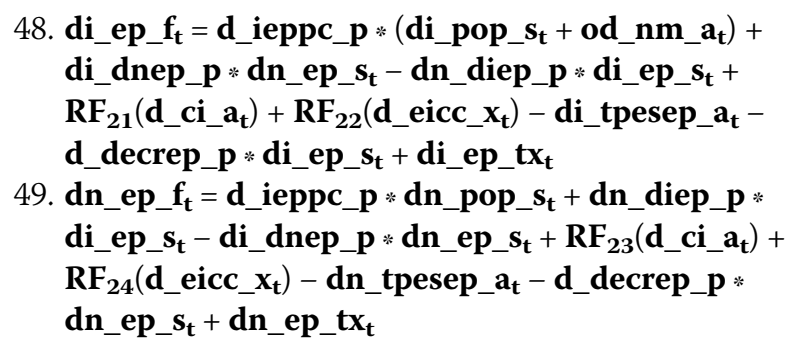

\section{Destination population flows:}

The immigrants' natural net birth rate is di_netbr_p and the natives' dn_netbr_p. Their immigrant population rises due to immigration (od_nm_a), falls when its HP pc stock rises above the death threshold, and depends on a TNE impact. The native group follows suits without arrivals. The population flows (immigrants: di_pop_f, natives: dn_pop_f) are given by:

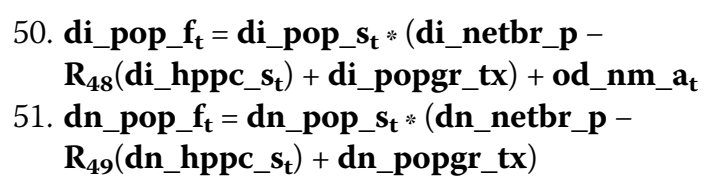

\section{Stocks and time:}

If the end time (endtime_p) has not arrived, the model updates its stock variables using their flows, advances $t$, and computes another cycle starting in eq. (1); else, it stops. 
Table 1 Input values for scenario S1

\begin{tabular}{|c|c|}
\hline \multicolumn{2}{|l|}{ Controllers } \\
\hline Arrival & $1 \ldots 1$ \\
\hline Conflict & $1 \ldots 1$ \\
\hline \multicolumn{2}{|l|}{ Scenarios (60 periods) } \\
\hline Number of arrivals per period & $0 \ldots 0$ \\
\hline Arrivals' HP pc & $0 \ldots 0$ \\
\hline Conflict intensity & $0 \ldots 0$ \\
\hline EICC intensity & $0 \ldots 0$ \\
\hline HC capacity & $4200 \ldots 4200$ \\
\hline ES capacity & $4200 \ldots 4200$ \\
\hline Native host HC pc impact of TNE & $-1 \ldots-1$ \\
\hline Immigrant $\mathrm{HC}$ pc impact of TNE & $-1 \ldots-1$ \\
\hline Native host other TNE impacts & $0 \ldots 0$ \\
\hline Immigrant TNE impacts & $0 \ldots 0$ \\
\hline $\mathrm{HC}$ quality provided to native hosts & $1 \ldots 1$ \\
\hline $\mathrm{HC}$ barriers facing native hosts & $0 \ldots 0$ \\
\hline ES quality provided to native hosts & $1 \ldots 1$ \\
\hline ES barriers facing native hosts & $0 \ldots 0$ \\
\hline $\mathrm{HC}$ quality provided to immigrants & $1 \ldots 1$ \\
\hline $\mathrm{HC}$ barriers facing immigrants & $0 \ldots 0$ \\
\hline ES quality provided to immigrants & $1 \ldots 1$ \\
\hline ES barriers facing immigrants & $0 \ldots 0$ \\
\hline HC/ES capacity splits & $1 \ldots 1$ \\
\hline \multicolumn{2}{|l|}{ Initial stocks } \\
\hline Immigrant population stock & 100 \\
\hline Native host population stock & 2000 \\
\hline Immigrant HP pc stock & 48 \\
\hline Native host HP pc stock & 48 \\
\hline Immigrant EP stock & 47 \\
\hline Native host EP stock & 47 \\
\hline \multicolumn{2}{|l|}{ Parameters } \\
\hline End-time & 60 \\
\hline Native host HP pc spillover on immigrant HP pc & 0 \\
\hline Immigrant spillover on native host HP pc & 0 \\
\hline Native EP spillover on immigrant EP pc & 0 \\
\hline Immigrant EP spillover on native host EP & 0 \\
\hline Native host birth rate & 0.001 \\
\hline Immigrant birth rate & 0.001 \\
\hline Individually created EP & 0 \\
\hline EP decay rate & 0 \\
\hline HP pc threshold for HC need & 48 \\
\hline EP threshold for ES need & 48 \\
\hline EP threshold for impacting HP pc & 48 \\
\hline HP pc threshold for death & 50 \\
\hline HP pc natural wear \& tear & 2 \\
\hline
\end{tabular}

Table 1 Input values for scenario S1 (Continued)

\begin{tabular}{ll}
\hline HP pc self-healing & 0 \\
HP pc variance & 0 \\
\hline
\end{tabular}

52. if $\mathbf{t}<$ endtime_p:

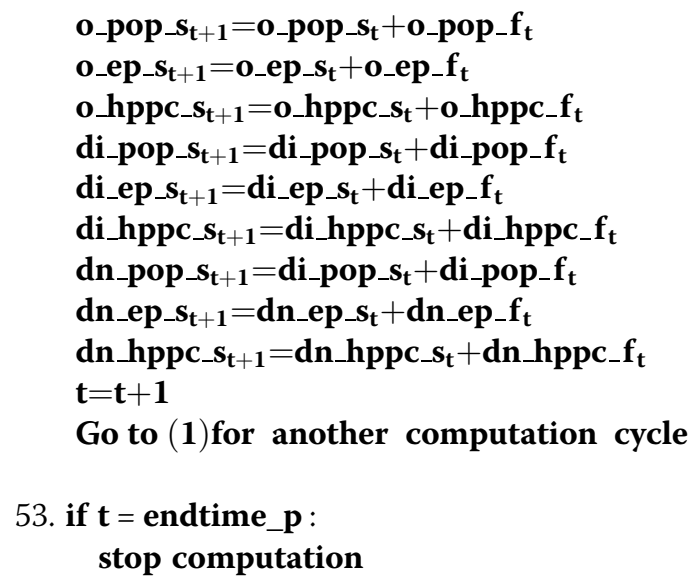

\section{Results}

We simulate the pilot model for four 60-period host-area storylines (S1-S4) focusing on health problems (HP), health care $(\mathrm{HC})$, population, and sensitivity analyses. The input values are synthetic (as noted), and we compute using Excel. In storyline S1, natives and immigrants have full access to perfect $\mathrm{HC}$ and environmental health services (ES). The HC and ES capacities do not change over time. There are no armed conflicts, ecological impacts of climate change (EICC), immigration, and intergroup HP and non-EICC environmental health problems (EP) spillovers. Storyline S2 adds climate migrants and HP spillovers to storyline S1, all else the same. Storylines S3 and $\mathrm{S} 4$ add $\mathrm{HC}$ barriers and imperfect $\mathrm{HC}$ for the immigrants to storyline S2, in turn, keeping all else as in S2.

\section{Storyline S1: perfect quality without arrival, barriers, \& spillovers}

Storyline S1 (Table 1) sets the qualities to 1 (perfect), barriers 0 (none), and capacity divisions 1 (short capacity divided by group shares in the need). The HC and ES capacities are 4200. The HC one (we will see) allows shortage; the ES level suffices and, together with our setting of the EP decay and individual creation to 0 , focuses ideas on HP. The HP pc impacts of the total non-EICC exogenous (TNE) factors are -1 by group and $t$, representing pro-health social determinants of health. Other TNE levels are 0 (to simplify). At t 0 , there are $100 \mathrm{im}$ migrants and 2000 natives. Their HP pc and EP stocks are 48 and 47, in turn. The thresholds for needing $\mathrm{HC} /$ ES and EP raising $\mathrm{HP} \mathrm{pc}$ are 48 , so at t 0 , no one needs $\mathrm{HC} / \mathrm{ES}$, and EP does not harm health (stocks $\leq$ thresholds). The HP pc death level should top the one for HC 

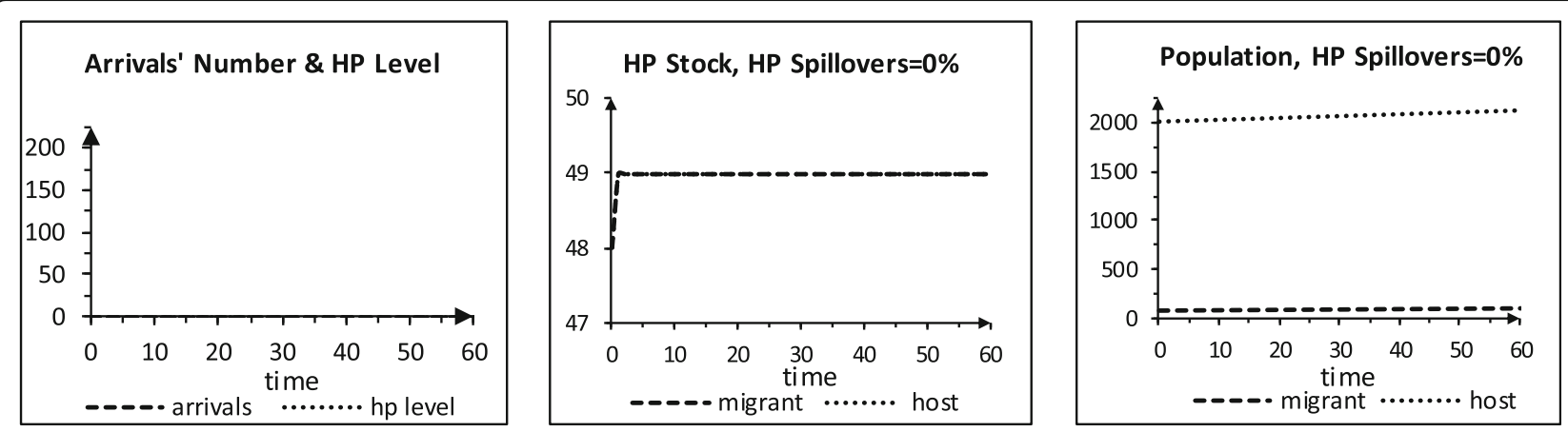

Note: HP is per capita, migrant stands for immigrants, and host for native hosts.

Fig. 1 Scenario S1, perfect quality, no arrival, no barriers, no spillovers

need. We use 50, so (we will see) death can occur. The net birth rate is $0.1 \%$ /period by the group, and HP pc wear \& tear is $2 /$ period. The self-healing and the variance of the HP pc impact of chance are 0 (to simplify). The parameters of the rise $(\mathrm{R})$ and rise-fall (RF) functions of conflict, EICC, and $\mathrm{EP}$ are 0 (as S1 sets the conflict and EICC levels to zero and, we shall see, generates EP < the threshold for raising HP pc at all $\mathrm{t}) \cdot \mathrm{R}_{48}\left(\mathrm{di}_{-} \mathrm{hppc} \mathrm{s}_{\mathrm{t}}\right)$ and $\mathrm{R}_{49}\left(\mathrm{di}_{-} \mathrm{hppc} \mathrm{s}_{\mathrm{t}}\right)$ for the population flows should give 0 if HP pc $\leq$ death level and rates rising above 0 if the HP pc stock rises above death. One possibility is $\mathrm{R}\left(\mathrm{hppc}_{\mathrm{t}}\right)=0.001\left(\mathrm{e}^{\left.\mathrm{MAX}\left(\mathrm{hppc}_{\mathrm{t}}-50\right), 0\right)}-1\right.$, by the group.

Let us walk through the model for storyline S1. At t 0 , the groups' EP and HP pc stocks are below the levels for impacting $\mathrm{HP}$ and needing $\mathrm{HC}$, in turn. For the HP pc flows, the effects are 0 for provision, EP, conflict, and arrival; 2 for wear \& tear; and -1 for the TNE factors; so, the flows are 1 by the

Table 2 Input values turning scenario S1 to scenario S2

\begin{tabular}{ll}
\hline Scenarios (60 periods) & \\
$\begin{array}{l}\text { Number of arrivals scenario (in } \\
\text { thousands) }\end{array}$ & $\begin{array}{l}10,10,10,100,125,150,175, \\
200,0 \ldots\end{array}$ \\
HP pc of arrivals scenario & $\begin{array}{l}48,48,48,55,55,55,55,55,0 \\
\text { Parameters }\end{array}$ \\
HP pc spillover - native hosts on \\
immigrants, case 1
\end{tabular}

group. The ES needs are 0 (as the associated EP stocks are smaller than the need threshold). As a result, the flow impacts of ES are 0. Other EP flow effects are 0, so the EP flows are 0 . The net birth rate is $0.1 \%$. Other population flow impacts are 0 . The immigrants' population flow is 0.1 and native 2 . At $\mathrm{t} 1$, the HP pc stocks are 49 [48 (prior) + 1 (flow)], EP stocks 47, the immigrant population 100.1, and the native 2002. The HC needs for provision are 1, by the group [HP pc stock (49) - need threshold (48)]. The groups' HP pc flows are 0 [2 (wear \& tear) -1 (quality) $\cdot 1$ (HC) -1 (TNE)], so the HP pc stocks at $t 2$ are 49 . The EP flows are 0 , so the EP stocks are 47 . The groups grow at $0.1 \% /$ period. This pattern repeats to $t 60$. Figure 1 shows the results.

\section{Storyline S2: arrival \& HP pc spillovers}

Storyline S2 (Table 2) resembles storyline S1, but new immigrants arrive, and health problems spill across the groups. The arrivals' number/period and HP pc scenarios rise from average levels and then decline to zero, representing the impact of an extreme weather event in the origin site. The decline captures the effects of, e.g., the event's damages and passing and the destination making it harder to get in (e.g., the United States after Hurricane Mitch). The arrivals' number is 10 in periods $1-3$ and 100 in 4 . It rises by $25 /$ period in periods $5-8$ and is 0 in 9-60. The arrivals' HP pc is 48 in periods $1-$ 3 (like the natives'), 55 in periods $4-8$, and 0 in $9-60$ (as the immigration stops). We set the HP pc spillover shares to $0,1 \%$, or $2 \%$, in turn, for a sensitivity analysis.

Figure 2 shows the results for storyline S2. For $0 \%$ spillovers, the natives' HP pc is like in S1. At t $1-3$, the arrivals are healthier than the resident immigrants, so the group's HP pc falls. At t 4-8, they are less healthy than their brethren, raising the group's HP pc and $\mathrm{HC}$ need. By $\mathrm{t} 9, \mathrm{HC}$ provision lowers the immigrants' $\mathrm{HP}$ pc to 49 . The native group grows $0.1 \%$ /period to $t 60$. The immigrant group grows at that rate at t $1-3$ and less 

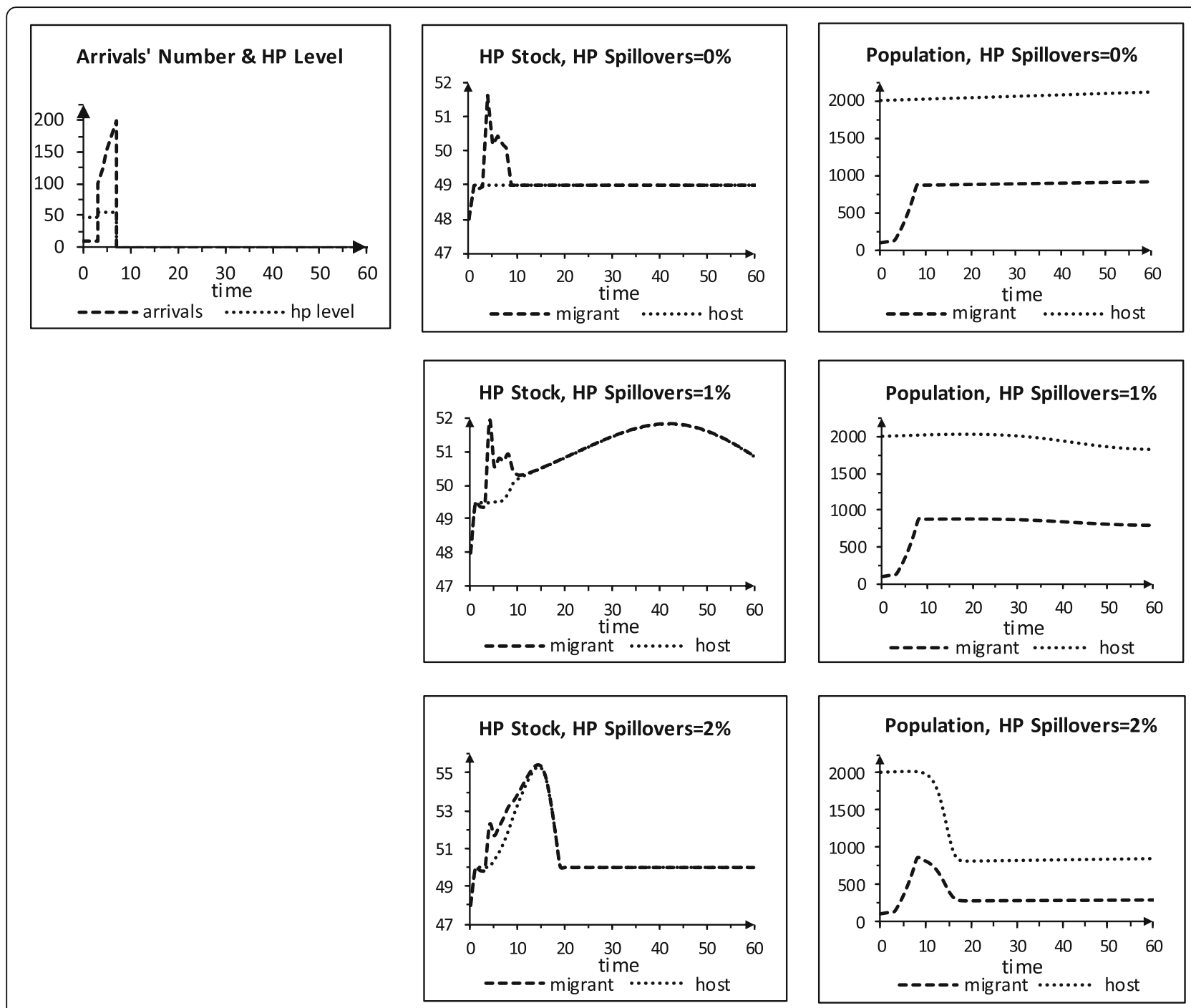

Note: HP is per capita, migrant stands for immigrants, and host for native hosts.

Fig. 2 Scenario S2, perfect quality, arrival, no barriers, spillovers

at $\mathrm{t} 4-8$ when its HP pc stock tops the death level (50). By $t$ 9, the groups' HP pc line up, and the immigrant group again grows $0.1 \%$ /period. For $1 \%$ spillovers, the immigrants' HP pc rises higher. The natives' HP pc increases when the arrivals are less healthy than the

Table 3 Input values turning scenario S2 to scenario S3

\begin{tabular}{ll}
\hline Scenarios (60 periods) & \\
HC barriers facing immigrants, case 1 & $0.25 \ldots 0.25$ \\
HC barriers facing immigrants, case 2 & $0.5 \ldots 0.5$ \\
Parameters & \\
HP pc spillover - immigrant on native host & 0.02 \\
HP pc spillover - native host on immigrant & 0.02 \\
\hline
\end{tabular}

immigrants. The total need for provision (TNFP) of HC tops capacity at $\mathrm{t} 6$, and the provided $\mathrm{HC}$ falls short of the overall needed level. The HP pc stocks equalize at $t$ 15 , peak at $\mathrm{t} 42$, and top death level at $\mathrm{t} 60$. Population decline starts at $t 19$. The TNFP falls after $t 39$ as the groups shrink but still tops capacity at t 60 . For $2 \%$ spillovers, the HP pc stocks exceed the death level even more, and the sizes of the two groups shrink faster. The immigrants have more HP than the natives since they absorb arrivals with HP. The TNFP falls below the HC capacity earlier than for the $1 \%$ spillovers, as there are now fewer people. The groups return to grow $0.1 \%$ / period but are smaller and less healthy than for the other cases. 

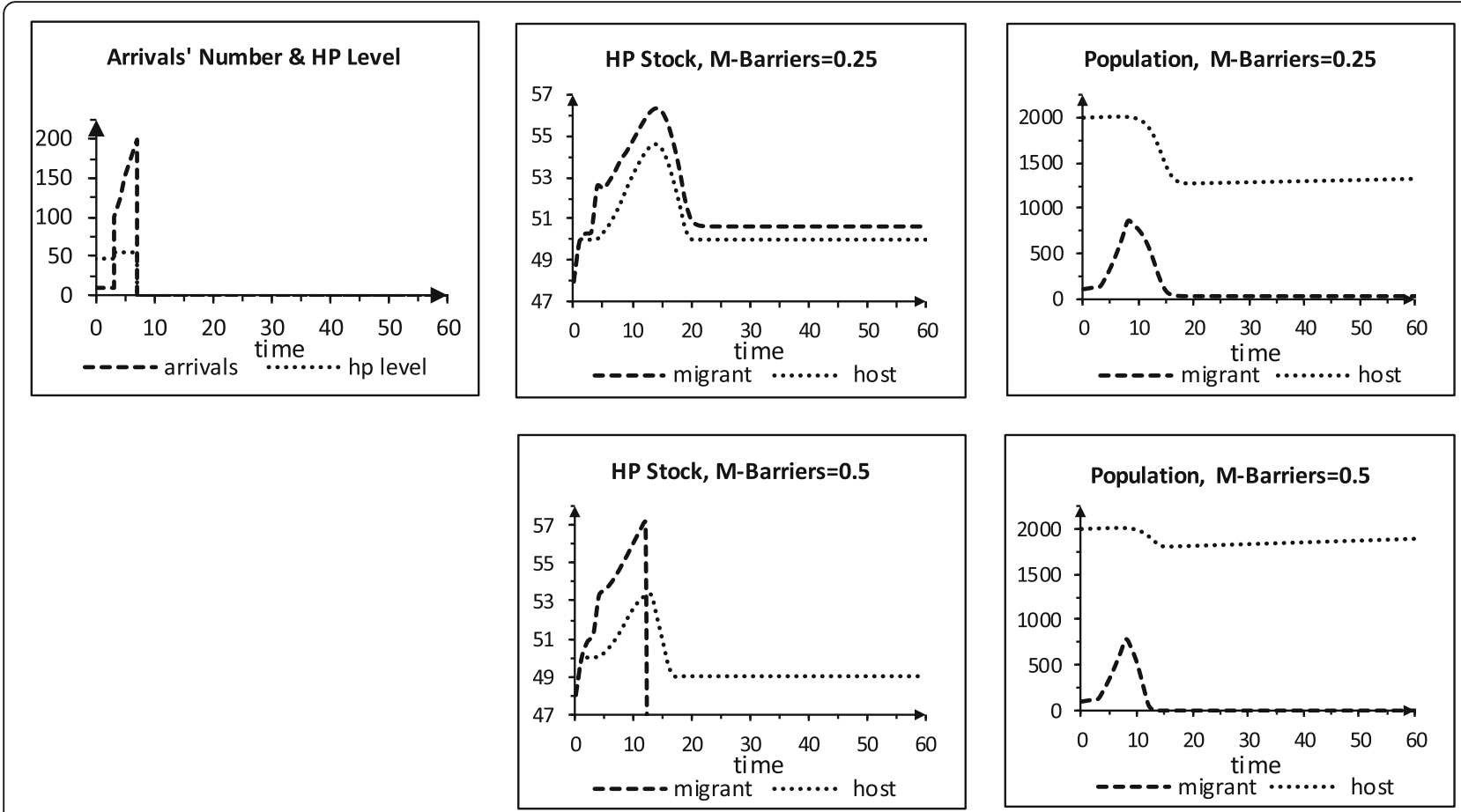

Note: HP is per capita, M and migrant stand for immigrants, and host for native hosts.

Fig. 3 Scenario S3, perfect quality, arrival, barriers for immigrants, 2\% spillovers

\section{Storylines S3 and S4: arrival, HP spillovers, HC barriers / imperfect quality}

Storyline S3 (Table 3) resembles storyline S2, except that the immigrant population now faces $\mathrm{HC}$ barriers (b) in the host area, and the intergroup HP pc spillovers equal $2 \%$. We examine two b values for sensitivity analysis: immigrants have $75 \%$ of the natives' access $(b=0.25)$ or $50 \%$ $(0.5)$. Figure 3 shows the outcomes. For $b=0.25$, the $\mathrm{HC}$ capacity does not suffice to provide the TNFP in periods $2-18$. The immigrants now get a smaller share of their $\mathrm{HC}$ need than in the $2 \%$ spillover \& zero barriers to $\mathrm{HC}$ simulated in storyline S2. As a result, their HP pc stock rises more, and the population reaches a lower minimum ( 21 vs. 278$)$ and end value (23 vs. 289 ). The natives' HP pc increases less than the immigrants', as they do not face barriers, and their population has higher

Table 4 Input values turning scenario S2 to scenario S4

\begin{tabular}{ll}
\hline Scenarios (60 periods) & \\
HC quality delivered to immigrants, case 1 & $0.75 \ldots 0.75$ \\
HC quality delivered to immigrants, case 2 & $0.5 \ldots 0.5$ \\
Parameters & \\
HP pC spillover - immigrant on native host & 0.02 \\
HP pc spillover - native host on immigrant & 0.02 \\
\hline
\end{tabular}

minimum (1265 vs. 845$)$ and end (1317 vs. 846$)$ values than in S2. The HP pc stocks steady at 50.01 for the natives and 50.67 immigrants, higher than for the baseline (50). For $b=0.5$, the immigrants' HP pc rises more than for $b=0.25$, and the immigrant population dies out in period 13. Total HC need then falls below capacity, and the native group again grows $0.1 \% /$ period, but it is smaller in period 60 than in period 0 (1898 vs. 2000).

Storyline S4 (Table 4) takes after Storyline S2, but the intergroup HP pc spillovers equal $2 \%$, and the group of the immigrants gets limited $\mathrm{HC}$ quality (q) in the host area. We use two q levels for sensitivity analysis: 0.75 (the immigrants get $\mathrm{HC}$ with $75 \%$ of the natives' perfect $\mathrm{HC}$ level) and 0.5 (they get $\mathrm{HC}$ with $50 \%$ of the $\mathrm{HC}$ quality the natives get). Figure 4 presents the simulation results. For $\mathrm{q}=0.75$, the immigrants' HP pc stock exceeds the natives' HP pc stock, and their group population declines. When the immigrants' HP pc stock stabilizes, they are less healthy than the natives, and their group is nearly gone. For $\mathrm{q}=0.5$, the immigrants' $\mathrm{HP}$ pc stock rises more than it increases for $\mathrm{q}=0.75$, and their group vanishes. The natives' HP pc stock then stabilizes at 49 , as it did in storyline S1. Their population returns to grow $0.1 \%$ per period from a higher level than for $\mathrm{q}=$ 0.75 and ends larger at t 60 (1863 vs. 1228). 

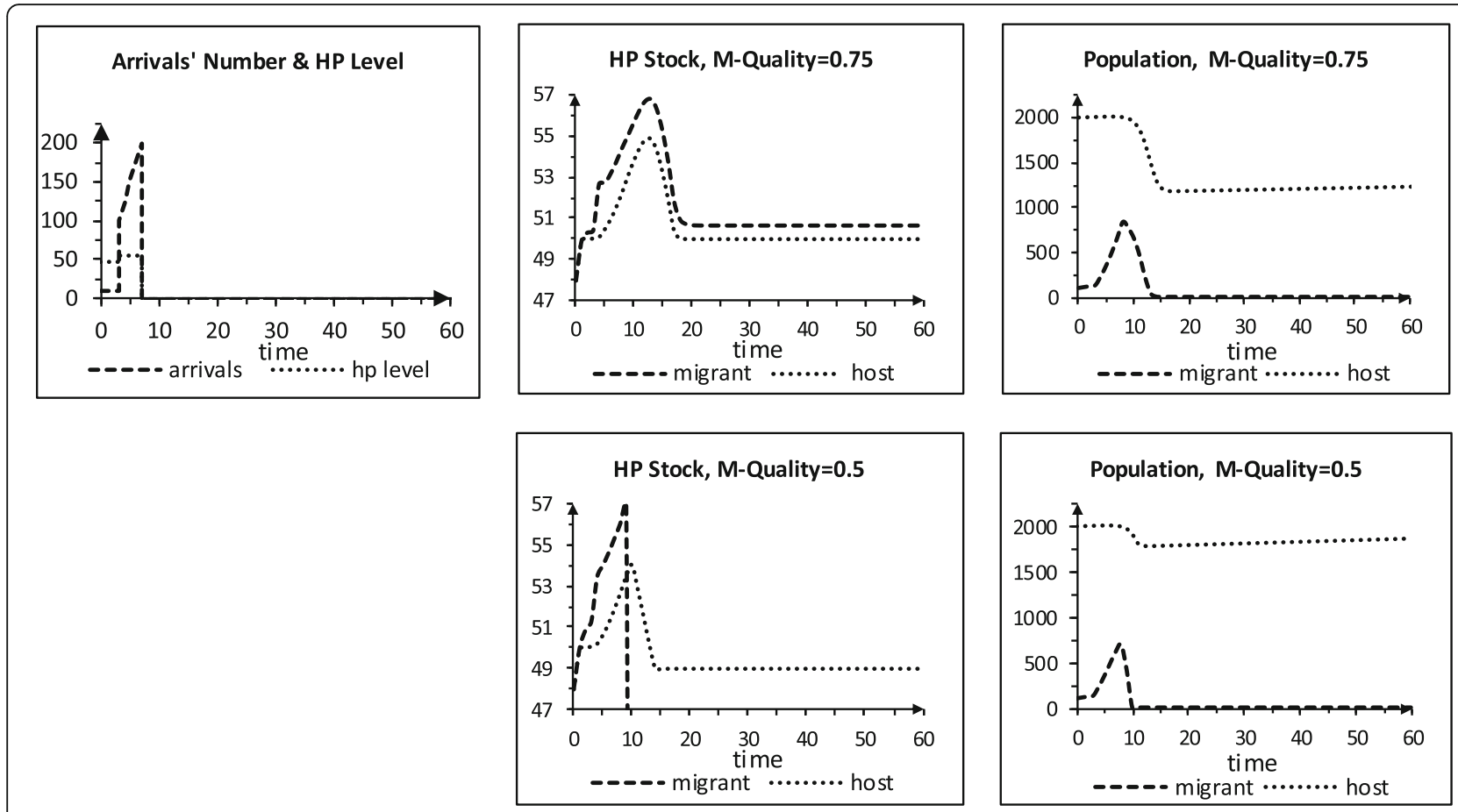

Note: HP is per capita, M and migrant stand for immigrants, and host for native hosts.

Fig. 4 Scenario S4, imperfect quality for immigrants, arrival, no barriers, 2\% spillovers

\section{Additional policy comparisons}

The policies $[\mathrm{b}=0, \mathrm{q}=0.75]$ in storyline $\mathrm{S} 4$ and $[\mathrm{b}=$ $0.25, \mathrm{q}=1$ ] in storyline $\mathrm{S} 3$ have similar impacts of provided $\mathrm{HC}$ on the $\mathrm{HP}$ pc flow, for a given $\mathrm{HC}$ need. The natives, in turn, get perfect $\mathrm{HC}$ quality and face no barriers. With this symmetry, why the HP pc stocks rise sooner and higher for $[\mathrm{b}=0, \mathrm{q}=0.75]$ than for $[\mathrm{b}=$ $0.25, \mathrm{q}=1]$ ? To streamline the discussion, we denote the $\mathrm{HC}$ capacity $\mathrm{c}$, the $\mathrm{HC}$ level the natives need $\mathrm{n}$, and the immigrants' $\mathrm{HC}$ need $\mathrm{m}$. In both cases, the total need for provision (TNFP) $>c$ for a while. If $c>$ TNFP, the provision impact on the HP pc flow is $q(1-b) m$ for the immigrants and $\mathrm{n}$ natives. If $\mathrm{c}<\mathrm{TNFP}, \mathrm{c}$ is divided by the groups' shares of the TNFP. The immigrants' share for $[\mathrm{b}=0, \mathrm{q}=0.75], \frac{0.75 \mathrm{~m}}{\mathrm{~m}+\mathrm{n}}$, is smaller than their share for $[\mathrm{b}=0.25, \mathrm{q}=1)], \frac{0.75 \mathrm{~m}}{0.75 \mathrm{~m}+\mathrm{n}}$. As a result, they get less HC, and their HP pc climbs sooner and higher for the former policy. This result also holds for the natives ( $\frac{\mathrm{n}}{\mathrm{m}+\mathrm{n}}<\frac{\mathrm{n}}{0.75 \mathrm{~m}+\mathrm{n}}$ ) and for the policy $[\mathrm{b}=0, \mathrm{q}=0.5)$ versus the policy $[\mathrm{b}=0.5, \mathrm{q}=1]$.

Next, we define the minimum sufficient $\mathrm{HC}$ capacity (MSHC) as the smallest level sufficing to provide the TNFP for $t$ 1-60, for each [b, q] policy. Which [b, q] policy has the smallest MSHC? This question has financial implication (capacity building is costly and $\mathrm{HC}$ cost rises with its quality) but is hard to answer since higher $\mathrm{b}$ raises $\mathrm{HP}$ pc and higher $\mathrm{q}$ reduces it and both impact the TNFP over time. We can find the MSHC per [b, q] policy by simulating for lower and lower capacity until the capacity first falls below

Table 5 Minimum sufficient HC capacity

\begin{tabular}{llllllll}
\hline $\begin{array}{l}\text { Immigrant } \\
\text { HC barriersc }\end{array}$ & $\begin{array}{l}\text { Immigrant } \\
\text { HC quality }\end{array}$ & HC capacity & $\begin{array}{l}\text { Immigrant } \\
\text { pop t 60 }\end{array}$ & $\begin{array}{l}\text { Native } \\
\text { pop t 60 }\end{array}$ & $\begin{array}{l}\text { Immigrant } \\
\text { steady HP }\end{array}$ & $\begin{array}{l}\text { Native } \\
\text { steady HP }\end{array}$ & $\begin{array}{l}\text { Time of } \\
\text { steady HP }\end{array}$ \\
\hline 0.25 & 0.75 & 7079 & 731 & 2119 & 51.56 & 50.03 & 17 \\
0.25 & 0.5 & 7758 & 187 & 2115 & 53.38 & 50.07 & 21 \\
0.5 & 0.75 & 6570 & 187 & 2115 & 53.38 & 50.07 & 21 \\
0.5 & 0.5 & 6538 & 0 & 2119 & 0 & 49 & 50 \\
0 & 1 & 6631 & 923 & 2123 & 50 & & 10 \\
\hline
\end{tabular}


the TNFP. At this point, a slightly larger level will do. In Table 5 , policy $[\mathrm{b}=0.5, \mathrm{q}=0.5]$ gives the smallest MSHC and policy $[\mathrm{b}=0.25, \mathrm{q}=0.5]$ the largest. For policy $[\mathrm{b}=0.5, \mathrm{q}=0.5]$, the immigrants' group vanishes, and the natives' HP pc stabilizes at 49 by t 24 . Policies $[\mathrm{b}=0.25, \mathrm{q}=0.5]$ and $[\mathrm{b}=0.5, \mathrm{q}=0.75]$ stabilize HP pc by t 21 (immigrant 53.4, native 50.1) with end populations $(187,2115)$. Policy $[\mathrm{b}=0.25$, q $=0.75]$ steadies sooner and lower [51.6, 50.03, $\mathrm{t}=17$ ] with larger end groups [731, 2119]. Policy $[\mathrm{b}=0, \mathrm{q}=$ 1] gives the largest end groups $(923,2123)$, fastest HP pc steadying $(t=10)$, lowest steady immigrants' HP pc (50) and second-lowest natives' one (50). Which policy is the "best"? DSMs can inform effects of policies but cannot decide for us which is "the best".

\section{Discussion}

Are these results credible? The key to evaluating the credibility of dynamic simulation models (DSMs) is the amount of theoretical and empirical evidence supporting their intended use from their development process, performance in simulations, and the quality of the decisions they drive [230, 231]. We apply this evaluation or validation approach to our model.

Our DSM integrates causal processes gleaned from prior empirical results. It is conceptually valid as these processes follow accepted theories and do not merely capture correlations. It is complete for its intended use to the extent that our survey of the prior results is. Our pilot depicts a simplified but not wholly untenable reality. Social science models usually look at composites; ours are simply are more aggregated. Our period of one does not suffice for comparing the model outputs to data but has no algorithmic effect. Modeling one origindestination (OD) pair is okay if its variables do not depend on other pairs' variables. Empirical social science models usually make this assumption for their unit of analysis. Modeling total populations is fine, though it prevents studying things by subsets. Our no OD conflict feature usually holds. Relaxing these assumptions is a worthy effort to be discussed. Our design can contain more detail and things we possibly missed; as pilot DSMs go, this is a good thing.

How realistic our input values are? Health care $(\mathrm{HC})$ and environmental health services (ES) with perfect quality and zero barriers, non-EICC environmental health problems (EP) with zero decay and individual creation, and health problems (HP) with zero impacts of chance and self-healing are ideals. Small EP effects on HP and ES (ours are zero) are quite common in the North. Zero climate change impacts in host areas do not exist, but the effects are still relatively small, far enough from the equator and poles. We use these ideal types as a baseline, a method going back to sociologist Max Weber. More $\mathrm{HC} /$
ES barriers and lower quality for immigrants than natives are typical; our $25-50 \%$ less quality and more hurdles are possible. Fixed HC/ES capacities, and no conflict usually hold for quite long whiles. The total needed HC/ES may exceed the capacity during crises, mainly in the South. An initial 5\% immigrant-native ratio and a $0.1 \%$ period net birth rate over a month to several years are in the empirical ballpark. Extreme weather events at times create a rise-fall pattern for emigrants per period and their HP upon landing. Our R function for the population impact of HP pc gives roughly the net birth rate if HP pc rises near the death level; this seems about right, as do HP spillovers like our $0-2 \%$. The total HP pc impact of EP, nonEICC exogenous factors, wear \& tear, self-healing, and chance is positive, illustrating that, without perfect $\mathrm{HC}$ quality, HP pc must finally top its death level. In sum, our non-ideal input values convey a general sense of realism.

Our simulations generate effects in line with associated theories. Restricting $\mathrm{HC}$ quality for a group raises its HP pc stock. HP pc rising above a threshold raises the need for $\mathrm{HC}$, and $\mathrm{HP} \mathrm{pc}$ rising above a higher threshold raises the death rate. HP spillover from one group to another increases the latter's HP pc stock. Provided HC with a better quality has a larger healing effect. Unmet $\mathrm{HC}$ need raises HP pc. Populations grow at their natural rates when their HP pc is below the threshold for needing HC. The arrival of climate migrants raises the immigrants' population; arrivals healthier than resident immigrants make the group healthier, and vice versa. HP pc of at least one group rises when the total needed $\mathrm{HC}$ tops the $\mathrm{HC}$ capacity. The sizes of these effects are imprecise from a real-world view (as our input values are synthetic). Their directions and dynamics are plausible and internally consistent and, like the sizes, react cogently in our sensitivity analyses.

The evidence presented above suggests our DSM suffices for its planned use as a basis for improving model realism. As we turn to this task, it is beneficial to put our work in a general context. Our model suggests societies restricting $\mathrm{HC} / \mathrm{ES}$ for immigrants may harm all their residents' health. When the total need for HC tops capacity, communities face a tough choice: whose needs will go unmet? Climate change makes running into this dilemma more likely by increasing HP and conflict risks and immigration speed and size. These points apply anywhere globally, though not necessarily in the same intensity.

As we wait for deep global mitigation of carbon emissions and recalling the large projected migration for this century, our work implies that societies valuing public health may need to adapt. The emerging research on climate migration and health advises easing migration pressure by developing needy origins $[18,20]$; this may work, but, with the current tendency of fossil-fuel and beef consumption rise with income, it may step up global warming. Raising HC/ES and entry walls for immigrants may 
ease capacity stress but harm health for all residents and boost unauthorized entry. Lowering the barriers may require building up HC/ES capacity, crowding out other public projects. With these competing effects, further policy analysis can benefit from more DSM research.

\section{Conclusion}

Recent studies call to develop a dynamic simulation model (DSM) of migration, population, public health, and armed conflict potential under climate change, taking account of other forces. We demonstrated that developing and using such a simulation model can help to understand relationships between these forces and policy implications in different places by changing input values, so it is a worthy endeavor. This paper shows we can start this development by joining system science principles and social science theories and findings and implements a mathematical proof-of-concept for such a model. The prior section motivates using our pilot DSM to identify modeling extensions to make it more realistic and less simplified. This section lays out a path on how to do that.

Separating our pilot's composite variables by their respective measured subtypes provides a natural starting point for further DSM development. The general forms of the equations in such a DSM would largely resemble ours, though mathematical complexity would rise. For example, a model with two types of health problems, all else as here, will have three more stocks, three more flows, and more equations, functions, auxiliary variables, probability distributions, parameters, scenarios, and initial stock values. Modeling the populations per site by subsets such as age-groups, males, females, immigrant types, immigrant-native families, and immigrants per origin-destination (OD) pair would further complicate things. For example, a model with two origin sites, all else as here, would have six more stocks and six more flows than our pilot. Its algorithm will mostly be like ours but include many more equations, variables, and parameters. Other extensions to increase realism include adding OD conflict (using our conflict algorithm), conflict proneness per site (using skewed distributions), stochastic extreme weather events per site (using our conflict method), and delays in the realization of effects.

With a more realistic DSM of climate migration and population health defined, the next stage of the model development is to set a real world-oriented period size and compare the computed outputs to their associated observed data. Finding a suitable period size may require iterative simulations, as a shorter period increases resolution but can create artificial instabilities. Scenarios for the exogenous variables would come from published sources. The model's parameters and function values could come from expert opinions, reported empirical results, and calibration (i.e., adjusting these values to improve the model fit to data).

The calibration effort, in turn, may proceed visually with graphs and tables or computationally by minimizing a certain fit function (e.g., $F I T=\sum_{t=0}^{T}\left(y_{t}-y_{t}\right)^{2}-$ where $y_{t}$ is output at time $t, y_{t}$ the related data point, and $\mathrm{T}$ the number of periods - by choosing parameters and function values within prespecified ranges around their empirical estimates. This effort may use all the available data for the exogenous variables, ensuring the simulation's outputs make sense, or use part of the data and compare the results to the portion set aside.

Generating meaningful projections of climate migration and population health by the storyline requires a DSM whose outputs sufficiently match data. Comparing forecasts between existing DSMs may provide further insight, though we think that this option is currently not available in our case. One may also validate DSMs by applying policies and comparing their actual effects to their forecasts. Taking this approach here should proceed with care, as things not working as projected may harm people.

Indeed, projections of fully validated DSMs may not emerge precisely even if the past policies continue, as no one knows the inputs values for the projected horizon. Scientifically assessing the future climate migration and public health trajectories for any given storyline is the unavoidably heaping projection of the variables of direct interest upon forecasts of other variables, raising the potential for a difference between the actual and the model's projected trajectories. DSMs might require revision now and then, even if their projection is deemed close enough to reality in some cases. New data coming on board may prompt modification of parameters, scenarios, functions, and even equations. In a sense, the process of developing and validating DSMs for conditional policy advice never really comes to an end.

\section{Supplementary information}

The online version contains supplementary material available at https://doi. org/10.1186/s12889-020-10120-w.

Additional file 1: Appendix. Defining the model variables and

parameters by type and alphabetical.

\begin{abstract}
Abbreviations
DSM: Dynamic simulation model; EICC: Ecological impacts of climate change; EP: Environmental health problems other than EICC (or non-EICC environmental health problems); ES: Environmental health services; HC: Health care; HIV/AIDS: Human immunodeficiency virus/acquired immunodeficiency syndrome; HP: Health problems; MSHC: Minimum sufficient HC capacity; OD: Origin-destination; pc: Per capita; PIMs: Authorized permanent international immigrants; TIMs: Authorized temporary international immigrant; TNE: Total non-EICC exogenous; TNFP: Total need for provision
\end{abstract}

Acknowledgments

Not applicable. 


\section{Author's contributions}

RR conceptualized and designed the study, developed the mathematical model, simulated the model, analyzed the results, and drafted the paper. The author read and approved the final manuscript.

\section{Author's information}

RR is a public, environmental, and international affairs professor in the School of Public and Environmental Affairs, Indiana University, Bloomington, Indiana, USA. His current research interests include migration and climate change, climate migration and health, the social collapse of ancient civilizations, economic development and war, and war and religion.

\section{Funding}

The author did not receive any financial assistance from any funding agency, nor asked for it.

\section{Availability of data and materials}

Not applicable.

\section{Ethics approval and consent to participate}

Not applicable.

\section{Consent for publication}

Not applicable.

\section{Competing interests}

The author declares no competing interests.

\section{Received: 5 March 2020 Accepted: 23 December 2020}

Published online: 26 March 2021

\section{References}

1. Taylor R, Rieger A. Rudolf Virchow on the typhus epidemic in upper Silesia. Sociol Health III. 1984;6(2):201-17.

2. N. Watts and others. The Lancet Countdown on health and climate change. Lancet. 2018;391(February 10):581-630.

3. IPCC. SR1.5: Summary for Policy Makers. Geneva: Intergovernmental Panel on Climate Change; 2014.

4. IMR. International Migration Report. New York: United Nations Population Division; 2020

5. IOM. Global Migration Indicators. Berlin: International Organization for Migration; 2018

6. Yayboke EK, Gallego CG. "Out of the shadows: shining a light on irregular migration," Rowman \& Littlefield and Center for Strategic International Studies (CSIS), New York and Washington DC; 2019.

7. DESA. Cross-national comparisons of internal migration. New York: United Nations; 2013

8. Gallup. Number of Potential Migrants Worldwide Tops 700 Million. Washington, DC: Gallup World Headquarters; 2017

9. UN. World Population Prospect: Net number of migrants by region, subregion, and country. New York: United Nations; 2017. p. 1950-2100.

10. UN-Habitat. Urbanization and Development. Nairobi: United Nations; 2017.

11. R. Jedwab and others. Demography, urbanization and development. J Urban Econ. 2017;98(1):6-16.

12. Stern N. The economics of climate change. New York: Cambridge University Press; 2007

13. IPBES. Thematic assessment report on land degradation and restoration. Bonn: Intergovernmental Science-Policy Platform on Biodiversity and Ecosystem Services; 2018

14. K. Rigaud and others. Groundswell: Preparing for Internal Climate Migration. Washington, DC: World Bank; 2018.

15. R. J. Nicholls and others. Sea-level rise and its possible impacts given a 'beyond $4^{\circ} \mathrm{C}$ world' in the twenty-first century. Philos Trans R Soc. 2012 ; 369(1934):161-81.

16. L. Marchiori and others. The impact of weather anomalies on migration in sub-Saharan Africa. J Environ Econ Manag. 2012;63(3):355-74.

17. Missirian A, Schlenker W. Asylum applications respond to temperature fluctuations. Science. 2017:358(6370):1610-4

18. P. N. Schwerdtle and others. Health and migration in the context of a changing climate: A systematic literature assessment. Environ Res Lett. 2020; (ERL-107913.R3):1-35. https://doi.org/10.1088/1748-9326/ab9ece.
19. A. d. Sherbinin and others. Preparing for resettlement. Science. 2011; 334(6055):456-7.

20. C. McMichael and others. Review: an ill wind? Climate change, migration, and Health. Environ Health Perspect. 2012;120(5):646-54.

21. M. Carballo and others. Climate change and displacement: Health challenges. Forced Migration Review. 2008;31(2):32-3.

22. IPCC. Fifth assessment report: impacts, adaptation, and vulnerability. New York: Intergovernmental Panel on Climate Change, Cambridge University Press; 2014

23. WHO. Health of Migrants: The Way Forward. Madrid: World Health Organization; 2010.

24. F. G. Schütte and others. Connecting planetary health, climate change, and migration. Lancet Planetary Health. 2018;2(2):e58-9.

25. C. J. Portier and others. A human Health perspective on climate change. J Curr Issues Globalization. 2014:6(4):621-710.

26. WHO. Operational framework for building climate-resilient health systems. Geneva: World Health Organization; 2015.

27. Future Earth and Belmont Forum, "Human Migration and Global Change: A synthesis of roundtable discussions," https://futureearth.org, Montreal, Canada, 2019.

28. S. Sellers and others. Climate change, human health, and social stability: addressing Interlinkages. Environ Health Perspect. 2019;127(4):1-10.

29. P. Tanuseputro and others. Simulation modeling to enhance population health intervention research for chronic disease prevention. Can J Public Health. 2019;110(1):52-7.

30. D. J. Currie and others. The application of system dynamics modeling to environmental health decision-making and policy. BMC Public Health. 2018; 18(402):1-11.

31. Ebi KL, Hess JJ. The past and future in understanding the health risks of and responses to climate variability and change. Int J Biometerol. 2017;61(9):71-80.

32. Hess J. Climate change health impact implications: looking into the future. In: Global climate change and human Health: from science to practice. San Fransisco: A Wiley Brand; 2016. p. 385-400.

33. El-Sayed AM, Galea S. "Ch. 17," in System Science and Population Health. New York: Oxford University Press; 2017. p. 217-20.

34. Lewis J, Swannell M. The macroeconomic determinants of migration. Bank England Staff Work Paper. 2018;729(1):1-30.

35. Dustmann C, Görlach JS. The economics of temporary migrations. J Econ Lit. 2016;54(1):98-136.

36. Tobia L. Exposure to violence and conflict: exploring predictors of unauthorized migration to the USA. Global Soc Welfare. 2017:4(2):71-80.

37. Lucas RE. Internal migration in developing economies. Geopolitics History Int Relat. 2016:8(2):159-91.

38. Echevarria J, Gardeazabal J. Refugee gravitation. Public Choice. 2017;169(4):269-92

39. F. Riosmena and others. Do Rainfall Deficits Predict U.S.-Bound Migration from Rural Mexico? Popul Res Policy Rev. 2013:32(1):129-58.

40. Alexeev A, Reuveny R. On weather disasters and international migration. Ann Geographical Stud. 2018;1(1):59-89.

41. Coniglio ND, Pesce G. Climate variability and international migration: an empirical analysis. Environ Dev Econ. 2015;20(4):434-68.

42. Spencer N, Urquhart M-A. Hurricane strikes and migration. Weather Climate Society. 2018:10(3):569-77.

43. H. Lu and others. Could smog pollution lead to the migration of local skilled workers? Res Conservation Recycling. 2018;130(1):177-87.

44. V. Koubi and others. Environmental stressors and migration: evidence from Vietnam. World Dev. 2016;79(3):197-210.

45. Dallmann I, Millock K. Climate variability and inter-state migration in India. CESifo Economic Studies. 2017:63(4):560-94.

46. P. Bohra-Mishra and others. Climate variability and migration in the Philippines. Popul Environ. 2018;38(3):286-308

47. C. Falco and others. Climate change, agriculture and migration. Sustainability. 2018;10(5):1-21.

48. N. Watts and others. The Lancet Health and climate change: policy responses to protect public health. Lancet. 2015;386(November 7):1861-914

49. Wintle M. Push-factors in emigration. Popul Stud. 1992:46(3):523-37.

50. Brach A, Koser K. Climate change, Health, and migration. Angle J. 2015;6(20):1-10.

51. M. Edelstein and others, "Health crises and migration," Forced Migration Review, 45, February, pp. 36-38, 2014.

52. Beine $M$, Parsons $C$ Climatic factors as determinants of internationa migration. Scand J Econ. 2015;117(2):723-67. 
53. Cashman G. What causes war? Lanham: Rowman \& Littlefield; 2014.

54. Mason TD, Mitchell SM. What do we know about civil wars? Lanham: Rowman \& Littlefield; 2016.

55. Choi SW, Salehyan I. No good deed goes unpunished. Confl Manag Peace Sci. 2013;30(1):53-75.

56. Salehyan I, Gleditsch KS. Refugees and the spread of civil war. Int Organ. 2006;60(2):335-66.

57. A. Dreher and others, "The Effect of Migration on Terror," CESifo Working Paper, vol. 6441, April, pp. 1-43, 2017.

58. F. Docquier and others. International migration: pacifier or trigger for military conflict? J Dev Stud. 2018;54(9):1657-79.

59. Côté I, Mitchell MI. Deciphering 'sons of the soil' conflicts. Ethnopolitics. 2017;16(4):333-51.

60. S. v. Baalen and M. Mobjörk. Climate change and violent conflict in East Africa. Int Stud Rev. 2018;20(4):547-75.

61. C. F. Schleussner and others. Armed-conflict risks enhanced by climaterelated disasters in ethnically fractionalized countries. PNAS. 2016;113(33): 9216-21.

62. M. Burke and others. Climate and conflict. Ann Rev Econ. 2015;7(1):577-617.

63. Gangopadhyay P, Nilakantan R. Estimating the effects of climate shocks on collective violence. J Dev Stud. 2018;54(3):441-56.

64. Reuveny R, Barbieri K. On the effect of natural resources on interstate war. Prog Phys Geogr. 2014;38(6):786-806

65. Nelson T. When disaster strikes. Peace Security Global Change. 2010;22(2): 155-74

66. Devlin C, Hendrix CS. Trends and triggers redux. Polit Geogr. 2014;43(6):27-39.

67. Price-Smith AT. Contagion and chaos: disease, ecology, and National Security in the era of globalization. Cambridge: The MIT Press; 2009.

68. Cohn SK. Pandemics: waves of disease, waves of hate from the plague of Athens to a.I.D.S. Hist Res. 2012;85(230):535-55.

69. Mustasilta K. From bad to worse? The impact(s) of Covid-19 on conflict dynamics. Conflict Series Eur Union Institute Security Studies. 2020;13(6): $1-8$.

70. Lee HF. Internal wars in history: triggered by natural disasters or socioecological catastrophes? The Holocene. 2018;28(7):1071-81.

71. K. Letendre and others. Does infectious disease cause global variation in the frequency of intrastate armed conflict and civil war? Biol Rev. 2010;85(3): 669-83.

72. Peterson S, Shellman S. AIDS and violent conflict: the indirect effects of disease on national security. Williamsburg: College of William and Mary; 2006.

73. Gonzalez-Torres A, Esposito E. Epidemics and conflict: evidence from the Ebola outbreak in Western Africa. Beer Sheva: Ben Gurion University; 2018

74. Desmidt S, Neat A. COVID-19 in Africa: A driver of conflict, or too early to tell? Maastricht: ECDPM; 2020.

75. Mehrotra R. "Contagion and conflict: evidence from India," in COVID economics: vetted and real-time papers. London: CEPR Press; 2020. p. 122-40.

76. M. Cervellati and others. Long-term exposure to malaria and violence in Africa. Econ Policy. 2018;33(95):403-46.

77. Montgomery M, Chakraborty J. Assessing the environmental justice consequences of flood risk. Environ Res Lett. 2015;10(9):1-11.

78. Lu Y. Hurricane flooding and environmental inequality. Socius. 2017:3(11):1-3.

79. T. W. Collins and others. Environmental injustice and flood risk. Reg Environ Chang. 2018;18(2):311-23.

80. T. A. Arcury and others. Pesticides present in migrant farmworker housing in North Carolina. Am J Ind Med. 2014;57(3):312-22

81. Funderburg R, Laurian L. Bolstering environmental (in) justice claims with quasi-experimental research design. Land Use Policy. 2015;49(1):511-26.

82. Liévanos RS. Race, deprivation, and immigrant isolation. Soc Sci Res. 2015; 54(1):50-67.

83. L. Pinault and others. Exposure to fine particulate matter air pollution in Canada. Health Rep. 2017;28(3):9-16.

84. Rüttenauer T. Neighbours matter. Soc Sci Res. 2018;70(February):198-211.

85. J. Ma and others. Inequality in Beijing. Ann Am Assoc Geographers. 2017; 107(1):109-29.

86. $X$. Zhao and others. Spatial associations between social groups and ozone air pollution exposure in the Beijing urban area. Environ Res. 2018;164(1): 173-83.

87. Gamlin J. Huichol migrant laborers and pesticides. Med Anthropol Q. 2016 30(3):303-20.
88. Tani M. Hukou changes and subjective well-being in China. Soc Indic Res. 2017;132(1):47-61

89. PEW. Mapping Public Benefits for Immigrants in the States. Washington, DC: The PEW Charitable Trusts; 2015.

90. Chen YB. The future of precarious status Migrants' right to Health Care in Canada. Alberta Law Rev. 2017:53(3):649-64.

91. DHS. Medicare card: Who can get it. Canberra: Department of Human Services, Australian Government; 2018.

92. Equi-Health. Summary Report on the MIPEX Health Strand \& Country Report. Brussels: International Organization for Migration Regional Office; 2016.

93. R. L. L. R. Guinto and others. Universal health coverage in 'one ASEAN': are migrant included? Glob Health Action. 2015;8(25749):1-16.

94. Alfaro-Velcamp T. Don't send your sick here to be treated, our own people need it more. Int J Migration Health Soc Care. 2017;13(1):53-68.

95. C. Arnold and others. A qualitative exploration of access to urban migrant healthcare in Nairobi, Kenya. Soc Sci Med. 2014;110(1):1-9.

96. Equi-Health. MIPEX Health Strand Country Report Turkey. Brussels: Int Org Migrat Reg Office; 2018.

97. Demintseva E, Kashnitsky D. Contextualizing migrants' strategies of seeking medical Care in Russia. Int Migr. 2016;54(5):29-42.

98. Office of Refugee Resettlement. "Refugees," U.S. Department of Health and Human Services. Washington, DC: Administration for Children \& Families; 2015.

99. Fozdar F, Banki S. Settling refugees in Australia. Int J Migration Border Stud. 2017;3(1):43-66.

100. IFHP. Interim Federal Health Program: summary of coverage. Ottawa: Canada.ca, Government of Canada; 2018.

101. Equi Health. "MIPEX Health Strand country reports," International Organization for Migration. Geneva: Switzerland; 2018.

102. V. Madyanova and others. Right for healthcare for migrants, refugees and stateless persons in Russia. Eur J Public Health. 2018;28(suppl_1):130.

103. F. L. H. Chuan and others. The health needs and access barriers among refugees and asylum-seekers in Malaysia. Int J Equity Health. 2018;17(120):1-15.

104. Nguma MM. The challenges and livelihood strategies of Pakistan's urban women refugees in Bangkok Thailand. Bangkok: Chulalongkorn University; 2017.

105. Silverman SJ, Griffiths M. Immigration detention in the UK: migration observatory briefing. Oxford: COMPAS, University of Oxford; 2018.

106. Minns J. Australia's Refugee Policy: Not a Model for the Word. Int Stud. 2018;55(1):1-21

107. O. o. R. Resettlement. Refugees and the Affordable Care Act. Washington, DC: U.S. Department of Health and Human Services; 2013.

108. Khoon CC. Universal Health Care. Health Human Rights J. 2015; Perspectives(11):1-5.

109. Q. Alemi and others. Determinants of Health care services utilization among first generation afghan migrants in Istanbul. Int J Environ Res Public Health. 2017; 14(201):1-12.

110. NILC. Immigrants and the affordable care act. Los Angeles: National Immigration Law Center; 2014

111. T. Huddleston and others. Migration Integration Policy Index (Excel file). Barcelona/Brussels: Barcelona Centre for International Affairs and Migration Policy Group; 2015.

112. Derr AS. Mental Health service use among immigrants in the United States. Psychiatr Serv. 2016;67(3):265-74.

113. A. Kalich and others. A scoping review of immigrant experience of Health care access barriers in Canada. J Immigr Minor Health. 2016;18(3):697-709.

114. J. Simon and others. Public health aspects of migrant health. Copenhagen: World Health Organization Regional Office for Europe; 2016.

115. Felix F. Barriers to access to healthcare services by immigrants population in Scandinavia. Tromsø: The Arctic University of Norway, Faculty of Health Sciences; 2017.

116. J. L. Bastos and others. Health care barriers, racism, and intersectionality in Australia. Soc Sci Med. 2018;199(February):209-18.

117. WHO. Health of refugees and migrants. Brazzaville: WHO African Region; 2018

118. Crush J, Tawodzera G. Medical xenophobia and Zimbabwean migrant access to public Health Services in South Africa. J Ethn Migr Stud. 2014; 40(4):655-70.

119. D. Drewniak and others. Do attitudes and behavior of health care professionals exacerbate health care disparities among immigrant and ethnic minority groups? An integrative literature review. Int J Nurs Stud. 2017;70(1):89-98. 
120. G. Pollock and others. Discrimination in the Doctor's office. Crit Soc Work. 2013;13(2):61-79.

121. Edge S, Newbold B. Discrimination and the Health of immigrants and refugees: exploring Canada's evidence base and directions for future research in newcomer receiving countries. J Immigrant Minority Health. 2014;15(1):141-8.

122. Tavares A. Perspectives of health care providers in Portugal on the provision of care to migrant patients with TB or HIV-TB co-infection. Eur J Public Health. 2018;28(suppl_1):161.

123. A. E. Arrey and others. Perceptions of stigma and discrimination in Health care settings towards sub-Saharan African migrant women living with HIV/ AIDS in Belgium. J Biosoc Sci. 2017;49(5):578-96.

124. R. Suphanchaimat and others. Challenges in the provision of healthcare services for migrants. BMC Health Serv Res. 2015;15(390):1-14.

125. K. Hacker and others. Barriers to health care for undocumented immigrants. Risk Management Healthcare Policy. 2016;8(10):175-83.

126. M. Winters and others. A systematic review on the use of healthcare services by undocumented migrants in Europe. BMC Health Serv Res. 2018; 18(30):1-10.

127. Alfaro MA, Bui NH. Mental Health professionals' attitudes, perceptions, and stereotypes toward Latino undocumented immigrants. Ethics Behav. 2018; 28(5):374-88.

128. Larchanché S. Intangible obstacles. Soc Sci Med. 2013;74(6):858-63.

129. Y. Wang and others. Fewer immigrants have ED visits in the United States. Am J Emerg Med. 2018;36(3):352-8.

130. Bauldry S, Szaflarski M. Immigrant-based Disparities in Mental Health Care Utilization. Socius. 2017;3(January-December):1-14.

131. Y. Wang and others. The association between immigration status and office-based medical provider visits for cancer patients in the United States. Med Care. 2017;55(6):629-35.

132. I. Mahmoud and others. Subjective reasons why immigrant patients attend the emergency department. BMC Emerge Med. 2016;15(4):1-6.

133. Tiagi R. Access to and utilization of health care services among Canada's immigrants. Int J Migration Health Soc Care. 2016;12(2):146-56.

134. Berchet C. Health care utilization in France. Revue d'Épidémiologie et de Santé Publique. 2014;61 (Supplement 2):S69-79.

135. V. Graetz and others. Utilization of health care services by migrants in Europe-a systematic literature review. Br Med Bull. 2017;121(1):5-18.

136. A. A. Abaerei and others. Health-care utilization and associated factors in Gauteng province, South Africa. Glob Health Action. 2017;10(1):1-9.

137. Karim AZ, Diah NM. Health seeking behavior of the Bangladeshi migrant Workers in Malaysia: some suggestive recommendations in Adjustive context. Asian Soc Sci. 2015;11(10):348-57.

138. H. Gu and others. Internal migration and maternal health service utilisation in Jiangsu, China. Trop Med Int Health. 2017;22(2):124-32.

139. Chitra GA. "Other socially constructed vulnerabilities," in Health inequities in India. Singapore: Springer Nature; 2018. p. 157-88.

140. V. Kiss and others. Building knowledge about health services utilization by refugees. J Immigr Minor Health. 2013;15(1):57-67.

141. Aspinall PJ. Identifying key vulnerable groups in data collections. London: UCL Institute of Health Equity, University College London; 2014.

142. C. Schneider and others. Disparities in health and access to healthcare between asylum seekers and residents in Germany: a population-based cross-sectional feasibility study. BMJ Open. 2015;5(11):1-10.

143. E. J. Hadgkiss and others. The physical health status, service utilisation and barriers to accessing care for asylum seekers residing in the community: a systematic review of the literature. Aust Health Rev. 2014;38(2):142-59.

144. W. M. Weiss and others. Utilization of outpatient services in refugee settlement health facilities. Confl Heal. 2011;5(19):1-15.

145. Hasanali SH. Immigrant-native disparities in perceived and actual met/ unmet. Need Med Care. 2015;17(5):1337-46.

146. J. Haj-Younes and others. Access to healthcare and unmet health needs among Syrian asylum seekers in transit and at arrival in Norway. Eur J Public Health. 2018;28(Supplement 1):76-7.

147. A. Busetta and others. A universal Health care system? Unmet need for medical care among regular and irregular immigrants in Italy. J Immigr Minor Health. 2018;20(2):416-21.

148. M. A. Schoevers and others. Health care utilisation and problems in accessing health care of female undocumented immigrants in the Netherlands. Int J Public Health. 2010;55(5):421-8.
149. C. o. Q. o. H. C. i. A. Institute of Medicine, Crossing the Quality Chasm: A New Health System for the 21st Century. Washington, DC: National Academy Press; 2001.

150. Orom H. Nativity and perceived healthcare quality. J Immigr Minor Health. 2016;18(3):636-43

151. S. S. Nielsen and others. Quality of Cancer Care among Foreign-Born and US-Born Patients with Lung or Colorectal Cancer. Cancer. 2011;116(23): 5497-506.

152. V. Porthé and others. Has the quality of health care for the immigrant population changed during the economic crisis in Catalonia (Spain)? Opinions of health professionals and immigrant users. Gac Sanit. 2018;32(5): 425-32.

153. P. Sauvegrain and others. Exploring the hypothesis of differential care for African immigrant and native women in France with hypertensive disorders during pregnancy. BJOG Int J Obstet Gynaecol. 2017;124(12):1858-65.

154. I. Keygnaert and others. What is the evidence on the reduction of inequalities in accessibility and quality of maternal health care delivery for migrants? Copenhagen: WHO Regional Office for Europe; 2016.

155. E. De Vito and others. Public health aspects of migrant health. Copenhagen: WHO Regional Office for Europe; 2016.

156. T. Maier and others. Mental health and healthcare utilisation in adult asylum seekers. Swiss Med Wkly. 2010;140(w13110):E1-8.

157. S. Mohammadi and others. Afghan migrants face more suboptimal care than natives: a maternal near-miss audit study at university hospitals in Tehran, Iran. BMC Pregnancy Childbirth. 2017;17(64):1-19.

158. S. V. Katikireddi and others. Assessment of health care, hospital admissions, and mortality by ethnicity. Lancet Public Health. 2018;3(5):e226-36.

159. L. Cacciani and others. Avoidable Hospitalization Among Migrants and Ethnic Minorities in Developed Economies. In: Access to Primary Care and Preventative Health Services of Migrants. Cham: Springer; 2018. p. 67-82.

160. T. D. Zuanna and others. Avoidable hospitalization among migrants and ethnic minority groups. Eur J Public Health. 2017;27(5):861-8.

161. van Rosse F. Ethnic inequalities in patient safety in Dutch hospital care. Amsterdam: BOXPress, University of Amsterdam; 2015.

162. C. Zimmerman and others. Migration and Health. PLoS Med. 2011;8(5):1-7.

163. Editorial. Migration and Health. Lancet Infect Dis. 2016;16(8):867.

164. Castelli F, Sulis G. Migration and infectious diseases. Clin Microbiol Infect. 2017;23(5):283-9.

165. Hall E, Cuellar NG. Immigrant Health in the United States: a trajectory toward change. J Transcult Nurs. 2016;27(6):611-26.

166. S. Kennedy and others. The healthy immigrant effect: patterns and evidence from four countries. J Int Migr Integr. 2015;16(2):317-32.

167. D. L. Parra-Casado and others. Self-rated health and wellbeing among the working-age immigrant population in Western Europe: findings from the European social survey (2014) special module on the social determinants of health. Eur J Pub Health. 2017;27(S1):40-6.

168. M. C. Cheung and others. Impact of immigration status on cancer outcomes in Ontario, Canada. J Oncol Pract. 2017;13(7):e602-12.

169. Dhadda A, Greene G. 'The Healthy Migrant Effect' for Mental Health in England: Propensity-score Matched Analysis Using the EMPIRIC Survey. J Immigr Minor Health. 2018;20(4):799-808.

170. E. Villalonga-Olives and others. Pregnancy and birth outcomes among immigrant women in the US and Europe. J Immigr Minor Health. 2017;19(6):1469-87.

171. A. F. Constant and others. A "healthy immigrant effect" or a "sick immigrant effect"? Selection and policies matter. Eur J Health Econ. 2018;19(1):103-21.

172. P. Bas-Sarmiento and others. Mental Health in immigrants versus native population. Arch Psychiatr Nurs. 2017;31(1):111-21.

173. Q. Z. Sohail and others. The risk of ischemic heart disease and stroke among immigrant populations. Can J Cardiol. 2016;31(9):1160-8.

174. V. Ranjbar and others. Physical and mental health inequalities between native and immigrant swedes. Int Migr. 2017;55(2):80-96.

175. Potarca G, Bernardi L. "The (un) healthy migrant effect," in social dynamics in Swiss society. Cham: Springer; 2018. p. 79-93.

176. Moyce SC, Schenker M. Migrant workers and their occupational Health and safety. Annu Rev Public Health. 2018;39(1):351-65.

177. Z. M. Vang and others. Are immigrants healthier than native-born Canadians? A systematic review of the healthy immigrant effect in Canada. Ethnicity Health. 2017;22(3):209-41.

178. E. Shor and others. The "Hispanic mortality paradox" revisited: Metaanalysis and meta-regression of life-course differentials in Latin 
American and Caribbean immigrants' mortality. Soc Sci Med. 2017; 186(1):20-33.

179. S. J. Ravensbergen and others. High prevalence of MRSA and ESBL among asylum seekers in the Netherlands. PLoS One. 2017;12(4):1-10,

180. V. Meier and others. Tuberculosis in newly arrived asylum seekers. Int J Hyg Environ Health. 2016;219(8):811-5.

181. M. T. Keboa and others. The oral health of refugees and asylum seekers. Glob Health. 2016;12(59):12-1.

182. F. Shawyer and others. The mental health status of refugees and asylum seekers attending a refugee health clinic including comparisons with a matched sample of Australian-born residents. BMC Psychiatry. 2017;17(76):1-12.

183. F. B. Belihu and others. Perinatal health outcomes of east African immigrant populations in Victoria, Australia. BMC Pregnancy Childbirth. 2016;16(86):1-11.

184. T. S. Betancourt and others. Comparing trauma exposure, mental Health needs, and service utilization across clinical samples of refugee, immigrant, and U.S.-origin children. J Trauma Stress. 2017;30(3):209-18.

185. O. Giuntella and others. Reason for immigration and immigrants' health. Public Health. 2018;158(1):102-9.

186. S. Brooker and others. Mental Health in an Invalidating Environment: The Case of Immigrant Detention in Australia. In: Challenging Immigrant Detention: Academics, Activists, and Policy-makers. Cheltenham: Edward Elgar; 2017. p. 195-221.

187. T. Filges and others. The impact of detention on the Health of asylum seekers: a systematic review. Res Soc Work Pract. 2018;28(4):399-414.

188. J. M. Linton and others. AAP Council on community pediatrics: detention of immigrant children. Pediatrics. 2017;139(4):1-13.

189. Chen J. Internal migration and health. Soc Sci Med. 2011;72(8):1294-301.

190. J. Mou and others. Health of China's rural-urban migrants and their families. Br Med Bull. 2014;106(1):19-43.

191. Y. Tong and others. Differences in the health-age profile across rural and urban sectors. Public Health. 2018;158(1):124-34

192. J. Lu and others. Mental health status, and suicidal thoughts and behaviors of migrant children in eastern coastal China in comparison to urban children. Child Adolesc Psychiatry Ment Health. 2018;12(13):1-17.

193. Green TL, Peters AC. Region of birth and child mortality among black migrants to South Africa. Migration Letters. 2016;13(3):359-76.

194. N. Mutombo and others. Health vulnerabilities among migrant/Mobile populations in urban settings of east and southern Africa. Afr Popul Stud. 2016;30(3):3047-59.

195. O. O. Akinyemi and others. Comparative study of mental health and quality of life in long term refugees and host populations in Oru-ljebu, Southwest Nigeria. BMC Res Notes. 2012;5(394):1-19.

196. N. Z. Khan and others. Displaced Rohingya children at high risk for mental health problems. Child Care Health Dev. 2019;45(1):28-35.

197. B. Ahmed and others. Humanitarian disaster for Rohingya refugees. Lancet Glob Health. 2018;6(5):e488-9.

198. N. R. Hussein and others. Prevalence of HBV, HCV and HIV infections among Syrian refugees in Kurdistan region, Iraq. Int J Infection. 2017;4(2):1-3.

199. Y. Duzkoylu and others. Physical trauma among refugees. J Environ Public Health. 2017;2017(8626275):1-5.

200. R. Pabayo and others. US state-level income inequality and risks of heart attack and coronary risk behaviors. Int J Public Health. 2015;60(5):573-88.

201. D. J. Dutton and others. Effect of provincial spending on social services and health on health outcomes in Canada. Can Med Assoc J. 2018;190(3):E6671.

202. B. H. Baltagi and others. Medical technology and the production of health care. Empir Econ. 2013;42(2):395-411.

203. E. Ng and others. Welfare states, labor markets, political dynamics, and population Health. Asia Pac J Public Health. 2016;28(3):219-31.

204. C. Chen and others. Short-term exposures to PM2.5 and cause-specific mortality of cardiovascular health in China. Environ Res. 2018;161(February): 188-94

205. C. R. Knittel and others. Caution, drivers! Children present. Rev Econ Stat. 2016;98(2):350-66.

206. K. A. de Oliveira and others. Association between race/skin color and premature birth. Revista de Saude Publica. 2018;52(26):1-11.

207. L. F. Berkman and others. Social Epidemiology. Oxford: Oxford University Press; 2014.

208. Malmusi D. Immigrants' health and health inequality by type of integration policies in European countries. Eur J Pub Health. 2015;25(2):293-9.
209. N. Blom and others. Ethnic health inequalities in Europe. Soc Sci Med. 2016; 158:43-51.

210. Levy BS, Sidel WW. Documenting the effects of armed conflict on population Health. Annu Rev Public Health. 2016;37(1):205-18.

211. Garry S, Checchi S. Armed conflict and public health: into the 21st century. J Public Health. 2019:1-11. https://doi.org/10.1093/pubmed/fdz095, no. PMID31822891.

212. Fisman D, Tuite A. Commentary: the DAGs of war. PNAS. 2019;116(48): $23880-2$.

213. P. Stoett and others. Comment: avoiding catastrophes: seeking synergies among the public health, environmental protection, and human security sectors. Lancet Glob Health. 2016;4(10):e680-1.

214. Berry I, Berrang-Ford L. Leishmaniasis, conflict, and political terror. Soc Sci Med. 2016;167(1):140-9.

215. Z. Wagner and others. Armed conflict and child mortality in Africa. Lancet. 2018;392(10150):857-65.

216. Iqbal Z, Zorn C. Violent conflict and the spread of HIV/AIDS in Africa. J Polit. 2010;72(1):149-62.

217. C. R. Wells and others. The exacerbation of Ebola outbreaks by conflict in the Democratic Republic of the Congo. PNAS. 2019;116(48):24366-72.

218. Joly M-P, Wheaton B. The impact of armed conflict in the country of origin on mental Health after migration to Canada. Soc Mental Health. 2015;5(2):86-105.

219. G. Øtsby and others. Organized violence and institutional child delivery. Demography. 2018:55(4):1295-316.

220. M. J. Lawrence and others. The effects of modern war and military activities on biodiversity and the environment. Environ Rev. 2015;23(4):443-60.

221. Maier L. War and environmental policy goals. Duke Univ J Sci Technol (Vertices). 2013:28(1):1-7.

222. Jha UC. Armed conflict and environmental damage. New Delhi: Vij Books; 2014

223. R. Reuveny and others. The effect of warfare on the environment. J Peace Res. 2011:47(6):749-61.

224. J. G. Elmore and others. Jekel's Epidemiology, Biostatistics, Prevention Medicine, and Public Health. St. Louis: Elsevier; 2020

225. Inyrayan A, Mahotra RK. Medical Biostatistics. New York: CRC Press; 2018.

226. Kirkwood BR, Sterne JAC. Essential of medical statistics. London: Blackwell; 2006.

227. Goodman MS. Biostatistics: essentials for clinical and public Health Research. London: Routledge; 2018.

228. Gerstman BB. Basic biostatistics: statistics for public Health practice. Burlington: Jones \& Bartlett Learning; 2015.

229. R. a. o. Bono. Non-normal distributions commonly used in Health, education, and social sciences: a systematic review. Front Psychol. 2018; 8(1602):1-6.

230. J. A. Kopec and others. Validation of population-based disease simulation models: a review of concepts and methods. BMC Public Health. 2010; 10(710):1-13.

231. I. S. Dahabreh and others. Modeling and Simulation in the Context of Health Technology Assessment: Review of Existing Guidance, Future Research Needs, and Validity Assessment. Methods Research Report. Rockville: Agency for Healthcare Research and Quality; 2017.

\section{Publisher's Note}

Springer Nature remains neutral with regard to jurisdictional claims in published maps and institutional affiliations.

Ready to submit your research? Choose BMC and benefit from:

- fast, convenient online submission

- thorough peer review by experienced researchers in your field

- rapid publication on acceptance

- support for research data, including large and complex data types

- gold Open Access which fosters wider collaboration and increased citations

- maximum visibility for your research: over $100 \mathrm{M}$ website views per year

At BMC, research is always in progress.

Learn more biomedcentral.com/submissions 